Check for updates

Cite this: RSC Adv., 2018, 8, 4634

Received 12th December 2017 Accepted 19th January 2018

DOI: 10.1039/c7ra13261a

rsc.li/rsc-advances

\section{The electrical modulus and other dielectric properties by the impedance spectroscopy of $\mathrm{LaCrO}_{3}$ and $\mathrm{LaCr}_{0.90} \mathrm{Ir}_{0.10} \mathrm{O}_{3}$ perovskites}

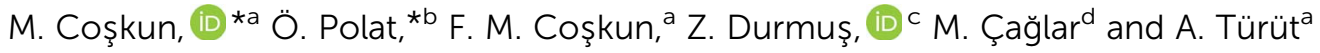

We have prepared $\mathrm{LaCrO}_{3}$ (LCO) and 10\% Ir doped LCO samples by the solid state reaction method and studied the electrical modulus and the other dielectric properties of the samples by means of the impedance spectroscopy in the $-100{ }^{\circ} \mathrm{C}$ to $100{ }^{\circ} \mathrm{C}$ range, with steps of $20{ }^{\circ} \mathrm{C}$. It has been clearly observed that the dielectric properties change due to Ir doping. The absolute dielectric constant value of Ir doped LCO has decreased and this reduction was attributed to decreasing $\mathrm{Cr}^{6+}$ ions which may play a vital role in space charge polarization and charge hopping. A plateau region appeared in the temperature-dependent real electrical modulus $M^{\prime}$ versus $f$ curves of the pure LCO sample while almost no plateau region is visible in the Ir doped LCO sample. The temperature-dependent imaginary modulus $M^{\prime \prime}$ versus $f$ curves has two peaks at each temperature; one of the peaks is at low frequency and the other at the high frequency region, which shifts through higher frequency region with increasing temperature. This originates from free charge accumulation at the interface with the increase of the temperature. Furthermore, it has been seen that the Ir doped LCO sample has higher impedance and resistance values than the undoped LCO sample at the same frequency and temperature. This phenomenon was attributed to doped Ir ions behaving like a donor in LCO because LCO is a p-type compound. Moreover, the activation energy values of $0.224 \mathrm{eV}$ and $0.208 \mathrm{eV}$ for LCO and of $0.161 \mathrm{eV}$ and $0.265 \mathrm{eV}$ for the Ir doped LCO have been obtained from the slopes of the $\rho_{\mathrm{dc}} v s$. $(k T)^{-1}$ curves, respectively. Also the activation energies were calculated from the slopes of the $f_{\max } v s$. $(k T)^{-1}$ curves and the obtained results from low frequency region were in good agreement with $\rho_{\mathrm{dc}} v s .(k T)^{-1}$ ones.
\end{abstract}

\section{Introduction}

The perovskite oxide compounds have the general stoichiometry of $\mathrm{ABO}_{3}$ formula in which $\mathrm{A}$ and $\mathrm{B}$ are cations and the A cation is larger than the $B$ cation. The perovskite oxide materials have grabbed considerable attention among scientists due to their electrical, dielectric, magnetic, thermal, mechanical, sensing and optical properties..$^{1-7}$ Additionally, the flexibility in the chemical composition of these materials offers excellent possibilities in terms of control of their structures via substitution of a number of transition metals into the A or B cation sites. ${ }^{8-12}$ Such properties make perovskite oxides very promising for several applications. The potential applications of these materials include ferroelectric

${ }^{a}$ Faculty of Engineering and Natural Sciences, Department of Engineering Physics, Istanbul Medeniyet University, 34700 Üskudar, Istanbul, Turkey. E-mail: mustafa. coskun@medeniyet.edu.tr

${ }^{b}$ Faculty of Engineering, Department of Industrial Engineering, Istanbul Kultur University, 34156 Bakirkoy, Istanbul, Turkey.E-mail: o.polat@iku.edu.tr ${ }^{c}$ Bağlar Mah., Gunesli Konutlar, No: 38, D-24, 34212, Bagcilar, Istanbul, Turkey

${ }^{d}$ Faculty of Science, Department of Physics, Anadolu University, Eskisehir, 26470, Turkey random access memory, multilayer ceramic capacitors, magnetic field sensors, solid oxide fuel cells (SOFCs), membranes, catalytic converters ${ }^{13-20}$ etc. Such wide range applications of these materials require us to understand their electrical and magnetic properties. Impedance spectroscopy is a well-developed tool to separate out the grain and grain boundary contributions to the total conductivity. Impedance technique acquires the electric response in a wide frequency range. The charge carrier in electric field could contribute to the electric response through motions such as charge displacement, dipole reorientation, space charge formation etc. ${ }^{17-23}$ The dielectric materials play an important role in the design of novel and high performances at electronic technologies. The dielectric, impedance, and modulus data often allow separately extracting additional useful information about the analysed dielectric materials. For instance, localized relaxations are calculated from the peaks at different frequencies in complex impedance or complex modulus versus frequency plots. The long-range fundamental conductivity results in exact overlapping of the modulus and impedance peaks. ${ }^{24-26,29-34}$ Especially, the investigation of electrical properties of these materials ${ }^{27,28}$ can provide us an insight for their application in sensors, optical memory, 
electro-optic devices and actuations in the microelectromechanical systems etc.

LCO is one of those perovskite oxides has been studied extensively in the literature. LCO is a p-type compound with wide optical band-gap ( $3.4 \mathrm{eV})$, high electrical conductivity, high resistive to corrosive, high physical and chemical stability in ambient and has orthorhombic crystalline structure. The electrical, dielectric, magnetic and optical properties of LCO can be changed by doping both A (La) and B (Cr) cation sites with transition metals that offer excellent possibility to researchers to large application areas. ${ }^{35-38}$ The doped transition metal type has significant impact on the LCO properties because it changes almost all LCO parameter including physical and chemical. Many doping studies have been conducted on the LCO with various transition metals including $\mathrm{Sr}^{39} \mathrm{Co}^{40} \mathrm{Ni}^{41} \mathrm{~V},{ }^{41} \mathrm{Cu},{ }^{41}$ $\mathrm{Mn},{ }^{42} \mathrm{Ca},{ }^{43} \mathrm{Pd}^{44}$ etc.

The aim of the present study is to investigate how transition element iridium, Ir, affects the electrical properties of LCO. It has been well documented that the ionic radius of the doped/ foreign cations and their mixed-valences are found to be the key parameters governing the electrical and magnetic properties of the parent materials. Ionic radius of Ir varies depending upon oxidation states, for instance, the ionic radius of $\operatorname{Ir}^{3+}$ is $0.068 \mathrm{~nm}$ but the ionic radius of $\mathrm{Ir}^{5+}$ is $0.057 \mathrm{~nm}$. Moreover, in the literature, it has been shown Ir may have +1 to +9 oxidation states. $^{45,46}$ Therefore, we have been inspired from such features of Ir element to study the electrical properties of LCO compound when it is doped by Ir. As far as we are concerned electrical and dielectric properties of Ir doped LCO study has not been conducted in the literature, yet.

We have experimentally investigated the absolute dielectric constant $|\varepsilon|$, electrical modulus $|M|$, impedance $|Z|$, the resistivity $\rho$, real $M^{\prime}$ and imaginary $M^{\prime \prime}$ of electrical modulus by means of the impedance spectroscopy of LCO and Ir doped LCO perovskite samples. The samples have been prepared by the conventional solid state reaction technique. The dielectric parameters versus frequency measurements have been conducted from $-100{ }^{\circ} \mathrm{C}$ to $100{ }^{\circ} \mathrm{C}$ range with steps of $20{ }^{\circ} \mathrm{C}$. Moreover, the $\rho_{\mathrm{dc}} v s .(k T)^{-1}$ and $f_{\max } \nu s .(k T)^{-1}$ curves have also been plotted to obtain the activation energy values of both samples.

\section{Experimental}

The pure and $\mathrm{Ir}$ doped $\mathrm{LaCrO}_{3}$ powders were prepared via conventional solid state reaction technique. For pure $\mathrm{LaCrO}_{3}$ synthesis, $\mathrm{La}_{2} \mathrm{O}_{3}$ (ACROS, 99.9\%) and $\mathrm{Cr}_{2} \mathrm{O}_{3}$ (ACROS, 99\%) powders were used as starting materials. For the preparation of Ir doped $\mathrm{LaCrO}_{3}$ powders, $\mathrm{IrO}_{2}$ (ACROS, 99.99\%), powders with mol\% (10\%) were mixed with $\mathrm{La}_{2} \mathrm{O}_{3}$ (ACROS, 99.9\%) and $\mathrm{Cr}_{2} \mathrm{O}_{3}$ (ACROS, 99\%) powders. For each powder the same synthesis steps were followed. Stoichiometric ratios of the mentioned powders were mixed in an agate mortar for $1 \mathrm{~h}$ with ethanol and calcined at $900{ }^{\circ} \mathrm{C}$ for $10 \mathrm{~h}$ in the air. The powders were then removed from the furnace and reground for homogeneity purpose. This step was pursued by the second calcination at $1200{ }^{\circ} \mathrm{C}$ for another $12 \mathrm{~h}$ in the air. Chemical stoichiometry of the powders was confirmed via Buker D8 Discover X-ray diffractometer (XRD) measurements. The XRD data of the synthesized powders have been presented in our previous study. ${ }^{44}$ Particle morphology of the synthesized powders was studied by a FEI scanning electron microscope (SEM) equipped with energy-dispersive X-ray spectrum (EDX). Xray photoelectron spectroscopy (XPS) (SPECS) was used to characterize the surface of Ir doped LCO powder and bonding states of related elements using AlK $\alpha$ X-rays. In this analysis, the calibration was made according to the C 1 s peak at $284.6 \mathrm{eV}$.

Pure and Ir doped $\mathrm{LaCrO}_{3}$ powders were pressed into $13 \mathrm{~mm}$ pellets at 10 tons pressure for 1 minute. After that, the pellets were gradually heated to $1150{ }^{\circ} \mathrm{C}$ for $4 \mathrm{~h}$ in air to sinter the targets. Novocontrol Broadband Dielectric/Impedance Spectrometer was employed for frequency depended electrical and dielectric property measurements. Temperature of the samples was gradually varied from $-100{ }^{\circ} \mathrm{C}$ to $100{ }^{\circ} \mathrm{C}$ with $20^{\circ} \mathrm{C}$ step.

\section{Results and discussion}

Fig. 1 and 2 show (a) and (b) SEM images with different magnification (c) EDX analysis results for LCO and $\mathrm{LaCr}_{0.90^{-}}$ $\mathrm{Ir}_{0.10} \mathrm{O}_{3}$ powders, respectively. As it can be seen from Fig. 1(a) and (b), LCO has spherical, oval and some irregular particle shapes. When it has been looked at Ir doped LCO powder in Fig. 2(a) and (b), the particles present non uniform morphologies. Moreover, images demonstrate the formation of cluster and agglomeration of particles. The energy-dispersive X-ray spectroscopy (EDX), a semi-quantitative elemental analysis technique, for the LCO and Ir doped LCO demonstrates in Fig. 1(c) and 2(c). EDX analysis has confirmed the presence of Ir in LCO sample.

XPS analysis was employed in order to investigate oxidation stage of Ir doped LCO powder and obtained results are presented in Fig. 3. As can be seen from Fig. 3(a) XPS analysis of Ir 4f was fitted into the two doublets (four peaks) due to the oxidized and metallic forms of Ir. The peaks at $61.58 \mathrm{eV}$ and $64.55 \mathrm{eV}$ are corresponding the metallic $\mathrm{Ir}^{47}$ whereas the peaks at $62.95 \mathrm{eV}$ and $64.55 \mathrm{eV}$ are due to the oxidized form of $\operatorname{Ir}(4+),{ }^{47}$ respectively. Therefore, it can be said Ir has mixed oxidation states of 0 and $4+$ in the doped LCO. The ratio of peak areas for 0 and $4+$ valance states also calculated via Gaussian fitting, which are $28.1 \%$ for O oxidation and $71.9 \%$ for $4+$ valance states. Oxidation of $\mathrm{Cr}$ atom in LCO and Ir doped LCO has been studied as well. The peak levels at $575.61 \mathrm{eV}$ and $577.10 \mathrm{eV}$ showed that $\mathrm{Cr}$ has mixed oxidation sates of $3+$ and $6+\left(2 \mathrm{p}_{3 / 2}\right)^{48}$ in our studied Ir doped LCO sample and data are given in Fig. 3(b). The Gaussian fitting reveals the ratio of peak areas of $\mathrm{Cr}^{3+}$ as $61.34 \%$ and $\mathrm{Cr}^{6+}$ as $38.66 \%$ in the investigated sample. Also the peak levels at $575.78 \mathrm{eV}$ and $577.30 \mathrm{eV}$ showed that $\mathrm{Cr}$ has both $3+$ and $6+$ oxidation states for undoped LCO too and the result was given at Fig. 3(e) and the Gaussian fitting reveals that the ratio of peak areas of $\mathrm{Cr}^{3+}$ as $56.8 \%$ and $\mathrm{Cr}^{6+}$ as $43.2 \%$. Moreover, valence state of La has been inspected. Two peaks at $833.83 \mathrm{eV}\left(\right.$ for $3 \mathrm{~d}_{5 / 2}$ ) and $850.60 \mathrm{eV}\left(\right.$ for $3 \mathrm{~d}_{3 / 2}$ ) reveal the valance state of $\mathrm{La}$ is $3+$ in Ir doped LCO sample. ${ }^{49}$ Finally, we have performed XPS analysis on the oxygen oxidation state. O 1s 

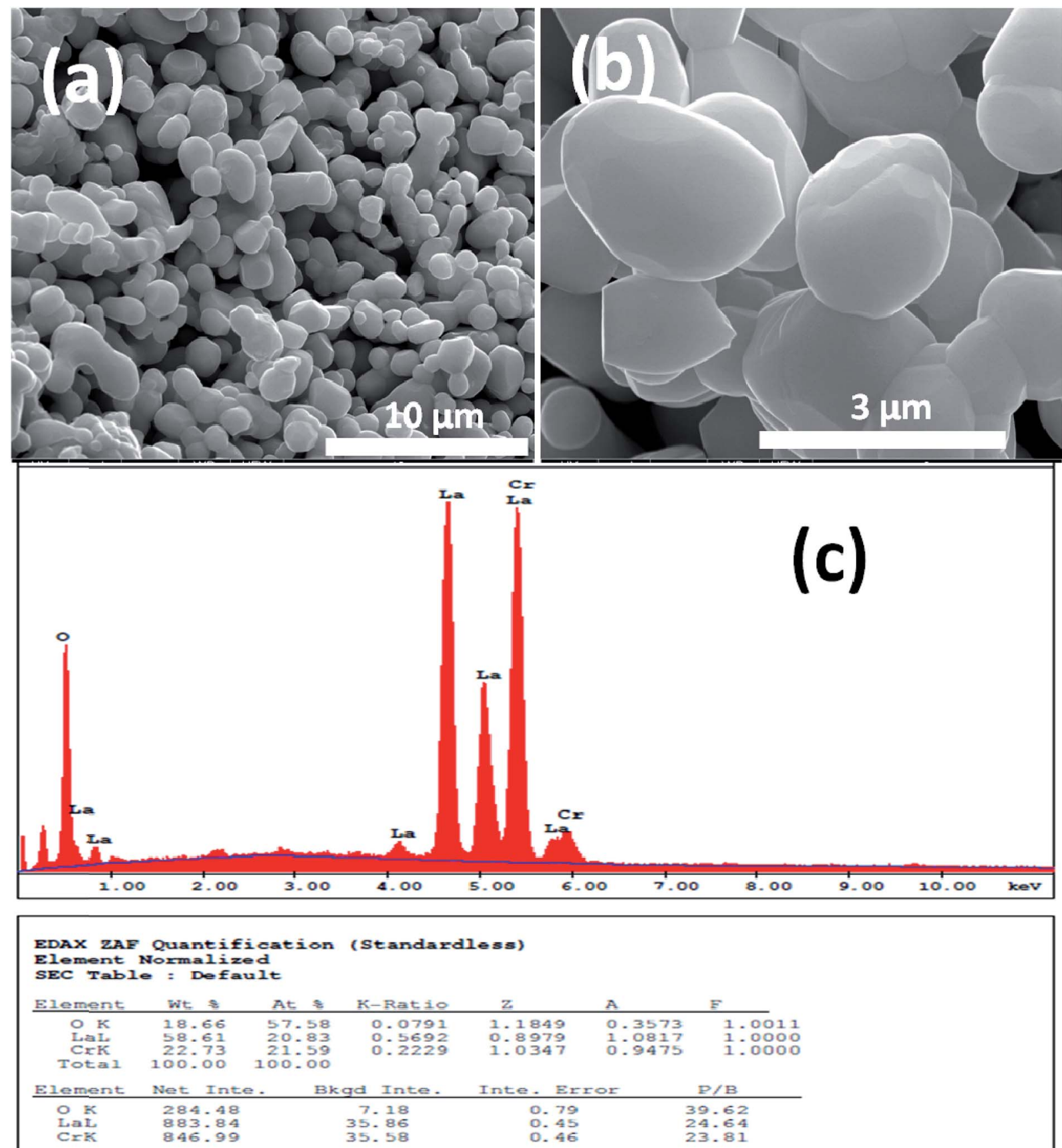

Fig. 1 ( $a$ and b) SEM images with different magnification (c) EDX analysis results for the pure $\mathrm{LaCrO}_{3}$ powders, respectively.

spectra have been investigated for Ir doped LCO sample. The obtained data have been represented in Fig. 3(d). It can be seen that $\mathrm{O}$ 1s spectra have high energy tail (second peak around 532 $\mathrm{eV}$ ). Such tail of $\mathrm{O} 1 \mathrm{~s}$ spectra are often seen in oxides and perovskite-like compounds. Even though the origin of these peaks is subjected to a number of discussions, ${ }^{50-55}$ Begreuther et al. introduced new ideas to illuminate the $\mathrm{O} 1 \mathrm{~s}$ high energy tails. ${ }^{53}$ They expressed that the tails may be related to (i) the various oxygen states which belong to different chemical bonds between oxygen-metal atoms, (ii) the defects within the crystal structure. In our studied Ir doped sample the presence of various oxidation states of Ir (metallic and $4+$ ) and/or defects support Begreuther et al. ideas. Both EDX and XPS inspections have demonstrated that the transition element Ir has been doped into $\mathrm{LaCrO}_{3}$ structure and also any impurity has not been observed in the these analysis results. Further, any extra peak has not observed in XRD results that confirm our compounds do not have impurity. ${ }^{4}$

Fig. 4(a) and (b) represent the frequency $(f)$ dependence of the dielectric constant $|\varepsilon|$ in the temperature range from $-100{ }^{\circ} \mathrm{C}$ to $100{ }^{\circ} \mathrm{C}$ with steps of $20^{\circ} \mathrm{C}$, (a) the pure $\mathrm{LaCrO}_{3}$ and (b) $\mathrm{LaCr}_{0.90} \mathrm{Ir}_{0.10} \mathrm{O}_{3}$, where $|\varepsilon|$ is in terms of a magnitude 

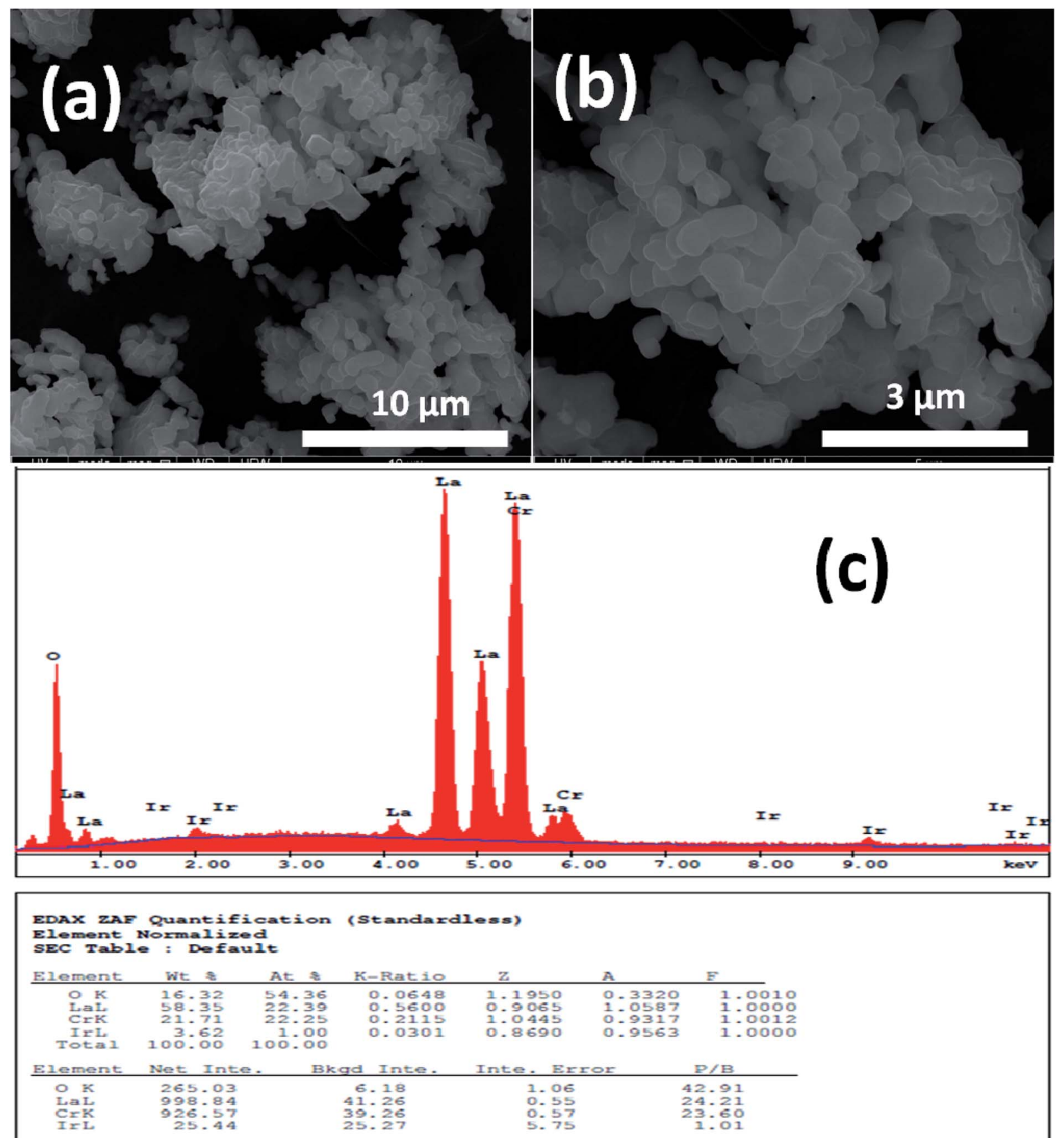

Fig. 2 (a and b) SEM images with different magnification (c) EDX analysis results for the $10 \%$ Ir doped $\mathrm{LaCrO}_{3}$ powders, respectively.

(absolute value) of $\varepsilon$ and the inset figures show temperature dependent dielectric constant $|\varepsilon|$ with different frequency. As seen from Fig. 4(a) and (b), the dielectric constant increases with increasing temperature at a given frequency (see inset figures). At the frequency of $1.0 \mathrm{~Hz}, \mathrm{LCO}$ sample has the $\varepsilon$ values of approximately $10^{4}$ at $-100^{\circ} \mathrm{C}$ and $3 \times 10^{7}$ at $100^{\circ} \mathrm{C}$, whereas $10 \%$ Ir doped LCO sample has the $|\varepsilon|$ values of approximately 180 at $-100{ }^{\circ} \mathrm{C}$ and $6 \times 10^{5}$ at $100^{\circ} \mathrm{C}$. That is, LCO sample has higher $\varepsilon$ value than the Ir doped LCO sample at a given frequency. We believe that such decrease in $|\varepsilon|$ value might be related to reduction of the number of $\mathrm{Cr}^{6+}$ ions, which may play a vital role on space charge polarization and charge hoppings, in LCO parent material due to substitution of $\operatorname{Ir}^{4+}$ ions. Liu et al. have shown that Sr doping into La in LCO structure boosts the conductivity and dielectric constant due to the generation of more $\mathrm{Cr}^{6+}$ ions. ${ }^{56}$ The XPS analysis confirmed that even though $\mathrm{Cr}^{3+}$ concentration increases from $56.8 \%$ to $61.34 \%$ for LCO and Ir doped LCO, the $\mathrm{Cr}^{6+}$ concentration lowers from $43.2 \%$ to $38.66 \%$ (see Fig. 3). Furthermore, it has been observed the plateau in the dielectric constant vs. frequency curves of LCO sample at each temperature. For example, the plateau of the curve for $\mathrm{LCO}$ at $-100^{\circ} \mathrm{C}$ ranges from approximately $|\varepsilon|=180$ at 

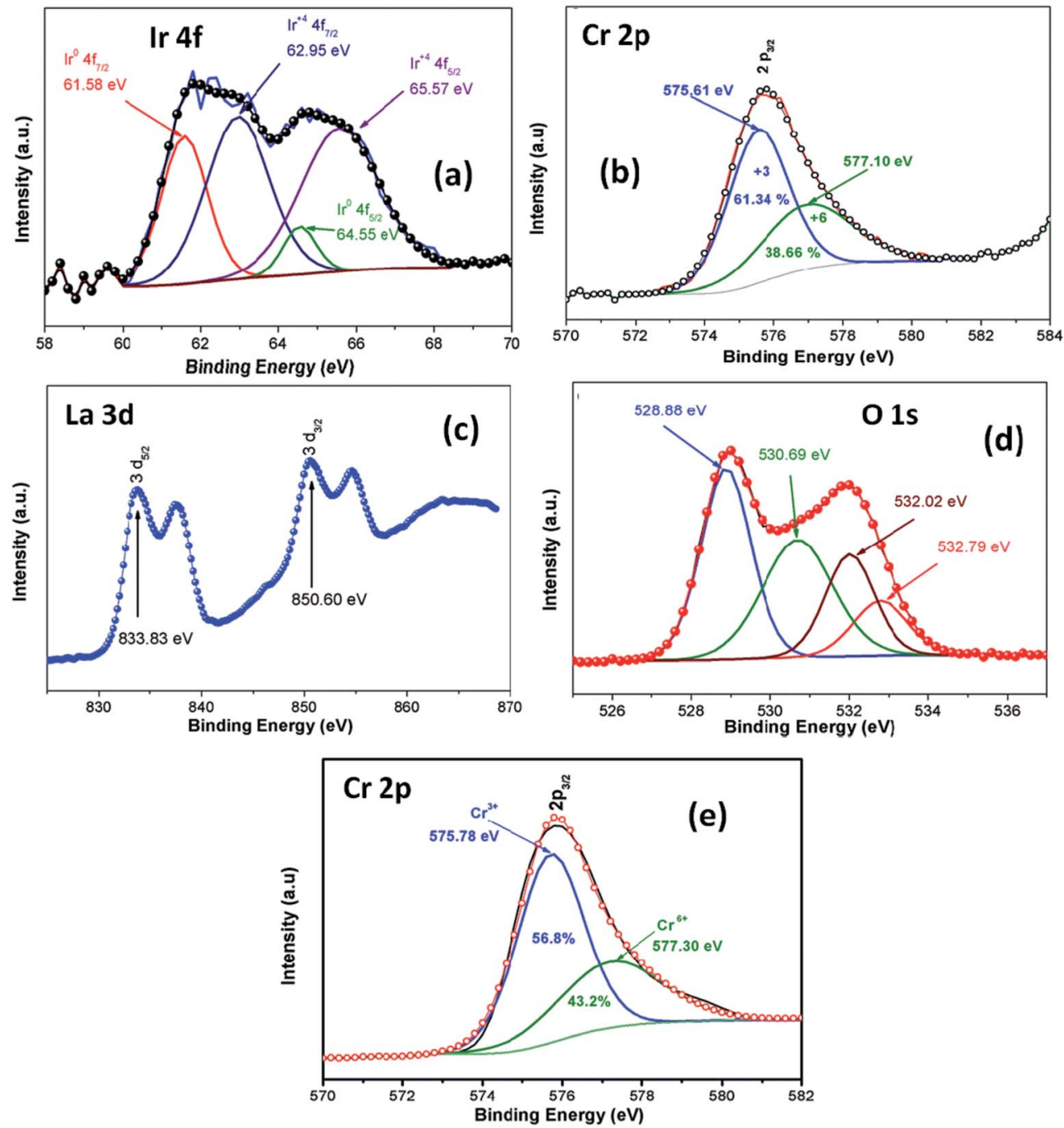

Fig. 3 XPS analysis of (a) Ir 4 f spectrum, (b) $\mathrm{Cr} 2 \mathrm{p}$ spectrum, (c) La 3d spectrum, (d) O 1s spectrum for Ir doped LCO and (e) Cr 2p spectrum for LCO.

$10^{2} \mathrm{~Hz}$ to $|\varepsilon|=125$ at $10^{4} \mathrm{~Hz}$, and plateau of the curve at $100^{\circ} \mathrm{C}$ begins from $|\varepsilon|=240$ at $3 \times 10^{5} \mathrm{~Hz}$ and beyond $10^{7} \mathrm{~Hz}$. The frequency range of the plateau in the $|\varepsilon|-f$ curves of LCO sample increases with increasing temperature again, the dielectric constant of LCO sample sharply decreases with increasing frequency to the starting point of the plateau at each temperature. Moreover, it can be seen from Fig. 4(a) and (b), the plateau for the doped LCO sample becomes more pronounced with increasing temperature while the plateau for the pure LCO sample has been observed at each temperature. The dielectric constant of LCO and Ir doped LCO samples sharply decreases with increasing frequency to a given frequency and then more slightly decreases to further frequencies at each temperature. The low and high frequency plateaus are attributed to extrinsic contributions from grain and grain boundary effects, respectively.

Fig. 5 shows the frequency dependence of the electrical modulus of (a) LCO and (b) Ir doped LCO samples, in the temperature range from $-100{ }^{\circ} \mathrm{C}$ to $100{ }^{\circ} \mathrm{C}$, where $|M|$ is in terms of a magnitude (absolute value) of the electrical modulus $M$ also the inset figures show electrical modulus $v s$. temperature with various frequencies, $10^{2}, 10^{3}, 10^{5}$ and $10^{7} \mathrm{~Hz}$. The electric modulus physically corresponds to the relaxation of the electric field in the material, so that the electric modulus represents the real dielectric relaxation process. The complex electric modulus, $M^{*}=M^{\prime}+\mathrm{j} M^{\prime \prime}$, is inversely proportional to permittivity of the material, $M^{*}=1 / \varepsilon^{*}$. The Complex modulus also provides an alternative approach (i) to analyze the electrical response of the materials and has been adopted by scientists to study relaxation phenomena in ceramics materials and ionic conductors, ${ }^{17-24}$ (ii) helps to confirm the ambiguity arising from the grain or grain boundary effect at elevated temperatures which may not be distinguished from complex impedance plots. The complex electric modulus has been discussed with both permittivity and impedance to study and analyze the contribution of the grain boundary on the relaxation mechanism of the materials also it offers us opportunities to investigate long-range conductions and localized dielectric relaxation 

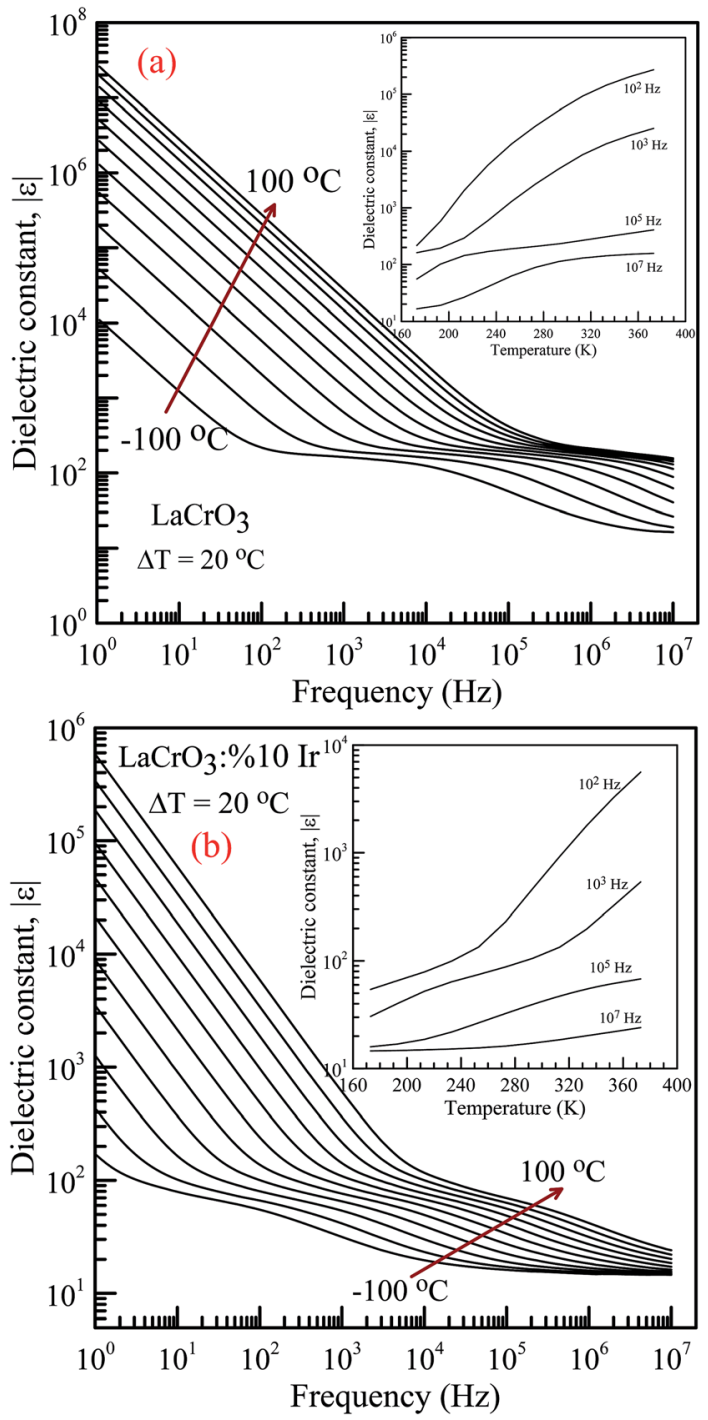

Fig. 4 Frequency dependence of the dielectric constant $|\varepsilon|$ in the temperature range from $-100{ }^{\circ} \mathrm{C}$ to $100{ }^{\circ} \mathrm{C}$ with steps of $20^{\circ} \mathrm{C}$, (a) pure $\mathrm{LaCrO}_{3}$ and (b) $\mathrm{LaCr}_{0.90} \mathrm{Ir}_{0.10} \mathrm{O}_{3}$. Inset figures show $|\varepsilon|$ vs. $\mathrm{T}$ at $10^{2}$, $10^{3}, 10^{5}$ and $10^{7} \mathrm{~Hz}$.

phenomenon in microscopic level. ${ }^{17-24}$ The complex electric modulus is the inverse of complex permittivity and is given as follows: ${ }^{17}$

$$
\begin{aligned}
M^{*} & =\frac{1}{\varepsilon^{*}}=\frac{1}{\left(\varepsilon^{\prime}-\mathrm{j} \varepsilon^{\prime \prime}\right)}=M^{\prime}+\mathrm{j} M^{\prime \prime} \\
& =\frac{\varepsilon^{\prime}}{\left[\left(\varepsilon^{\prime}\right)^{2}+\left(\varepsilon^{\prime \prime}\right)^{2}\right]}+\mathrm{j} \frac{\varepsilon^{\prime \prime}}{\left[\left(\varepsilon^{\prime}\right)^{2}+\left(\varepsilon^{\prime \prime}\right)^{2}\right]} .
\end{aligned}
$$

Moreover, it can also be expressed in terms of a derivative of complex impedance $Z^{*}{ }^{17}$

$$
M^{*}=M^{\prime}+\mathrm{j} M^{\prime \prime}=\mathrm{j} w \varepsilon_{0} Z^{*}=\mathrm{j} w \varepsilon_{0} Z^{\prime}-w \varepsilon_{0} Z^{\prime \prime}
$$

where $M^{\prime}$ and $M^{\prime \prime}$ are the real and imaginary parts of complex electric modulus $M^{*}$, respectively, and $\omega=2 \pi f$ is a radial
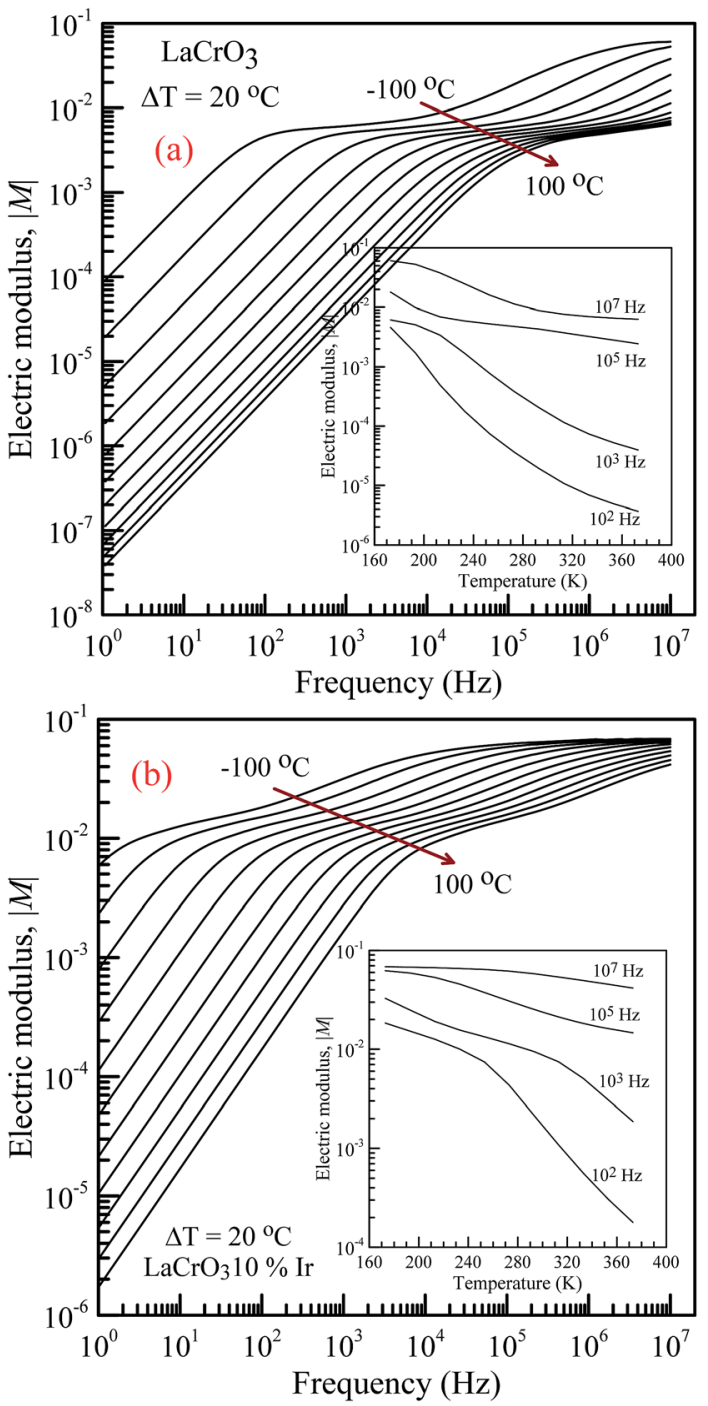

Fig. 5 Frequency dependence of the electrical modulus of both samples in the temperature range from $-100^{\circ} \mathrm{C}$ to $100{ }^{\circ} \mathrm{C}$ with steps of $20{ }^{\circ} \mathrm{C}$, (a) pure $\mathrm{LaCrO}_{3}$ and (b) $\mathrm{LaCr}_{0.90} \mathrm{Ir}_{0.10} \mathrm{O}_{3}$. Inset figures represent $|M|$ vs. $T$ at $10^{2}, 10^{3}, 10^{5}$ and $10^{7} \mathrm{~Hz}$.

frequency expressed in radians/second parameter and is related to the applied ac frequency $f$.

Fig. 6 shows the frequency dependence curves of the real part of electrical modulus, $M^{\prime}$, in the temperature range from $-100^{\circ} \mathrm{C}$ to $100^{\circ} \mathrm{C}$, (a) parent material LCO, inset shows the log$\log$ plots of the real part of modulus with frequency; (b) shows temperature dependent real part of electrical modulus with different frequency of LCO, (c and d) display the log-log plots and semi-log of the real part of modulus of the Ir doped LCO as function of applied frequency and inset figure (c) shows temperature dependent real part of electrical modulus Ir doped LCO, respectively. When looking at the temperature-dependent $M^{\prime}$ versus $f$ curves of both samples, the $M^{\prime}$ value increases with decreasing temperature at each frequency (see inset figures (b) and (c)), and it clearly seems that there is a difference in graphics due to the doped Ir. For example, in the log-log plots, the $M^{\prime}$ versus $f$ curve of LCO sample ranges from approximately 

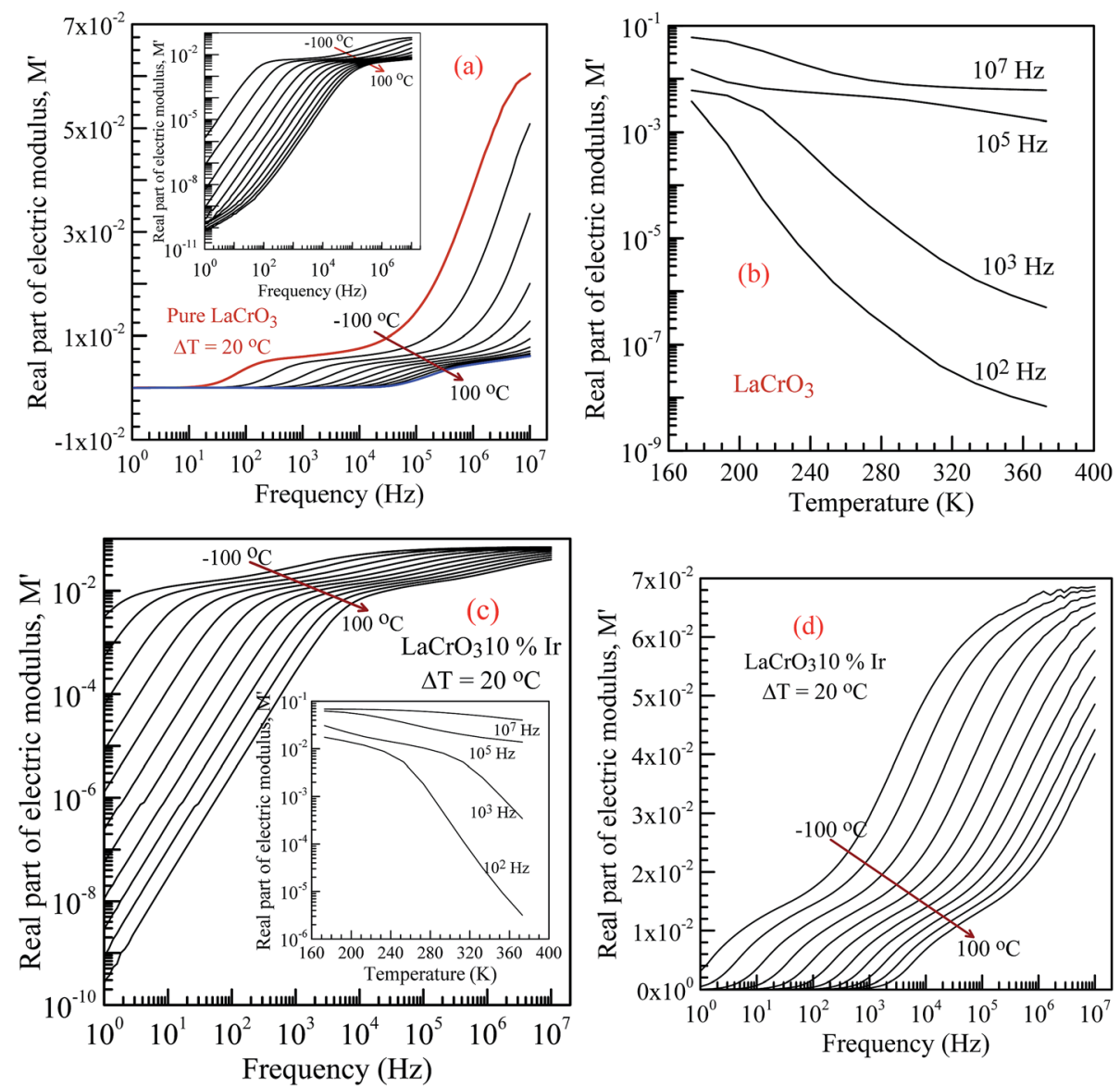

Fig. 6 Frequency dependence plots of the real part of electrical modulus, $M^{\prime}$ in the temperature range from $-100{ }^{\circ} \mathrm{C}$ to $100{ }^{\circ} \mathrm{C}$ with steps of $20^{\circ} \mathrm{C}$, (a) the pure $\mathrm{LaCrO}_{3}$, inset shows its log-log plots of the real part of modulus with frequency (b) temperature vs. $\mathrm{M}^{\prime}$ plot for LCO at $10^{2}, 10^{3}$, $10^{5}$ and $10^{7} \mathrm{~Hz}$. (c) $M^{\prime}$ vs. applied frequency for Ir doped LCO sample (inset figure shows temperature vs. $\mathrm{M}^{\prime}$ plot at $10^{2}, 10^{3}, 10^{5}$ and $10^{7} \mathrm{~Hz}$ ) and (d) semi-log of the real part of modulus with frequency of the $\mathrm{LaCr}_{0.90} \mathrm{Ir}_{0.10} \mathrm{O}_{3}$.

$1.6 \times 10^{-6}$ at $1.0 \mathrm{~Hz}$ to $6 \times 10^{-2}$ at $10^{7} \mathrm{~Hz}$ for $-100^{\circ} \mathrm{C}$, however, the curve of the Ir doped LCO varies from approximately $3 \times 10^{-3}$ at $1.0 \mathrm{~Hz}$ to $7 \times 10^{-2}$ at $10^{7} \mathrm{~Hz}$ for $-100^{\circ} \mathrm{C}$. When we look at the applied temperature of $100{ }^{\circ} \mathrm{C}$, the curve of LCO ranges from around $8 \times 10^{-11}$ at $1.0 \mathrm{~Hz}$ to $6 \times 10^{-3}$ at $10^{7} \mathrm{~Hz}$, but the curve of the Ir doped LCO ranges from nearly $2.5 \times 10^{-10}$ at $1.0 \mathrm{~Hz}$ to $4 \times$ $10^{-2}$ at $10^{7} \mathrm{~Hz}$. That is, the $M^{\prime}$ versus $f$ curve of the Ir doped LCO sample changes in a narrower range compared to that of the pure LCO at $-100{ }^{\circ} \mathrm{C}$. The change range expands with increasing temperature. As can be seen from the Fig. 6, the real part of electrical modulus, $M^{\prime}$, of both samples increases with boosting frequency at a given temperature, and it reaches a constant value at high frequencies. Moreover, when we look at the temperaturedependent semi-log $M^{\prime}$ versus $f$ curves of both samples, Fig. 6(a) inset and (c), a plateau region seems in the $M^{\prime}$ versus $f$ curves of LCO sample whereas no plateau region almost is visible in those of the Ir doped LCO sample at each temperature.

Fig. 7 shows the frequency dependence curves of the imaginary part of electrical modulus, $M^{\prime \prime}$ in the temperature range from $-100{ }^{\circ} \mathrm{C}$ to $100^{\circ} \mathrm{C}$ with steps of $20^{\circ} \mathrm{C}$, (a) LCO and (b) the Ir doped LCO, respectively. It is clearly seen that step like behavior was observed for both parent LCO and Ir doped LCO. It is clearly realized from Fig. 7(a) and (b) that $M^{\prime \prime}$ versus $f$ curves have two peaks at each temperatures, one of the peaks is at low frequency and other at high frequency region. It can be noticed that those peaks moves to higher frequency region via escalation of applied temperature. Such shift originates from free charge accumulation at the interface with the increase of the temperature. Thus, the increase in the charge carrier mobility decreases the relaxation time. The fact that the peaks shift to the higher frequency region with the increasing temperature indicates that dielectric relaxation is a thermally activated process in which the hopping mechanism of charge carriers dominates intrinsically. As can be seen from the figures, both peaks of the Ir doped LCO sample appears in the studied frequency range, 1.0 to $10 \mathrm{MHz}$. The second peak for parent LCO sample shifts towards frequencies over $10^{7} \mathrm{~Hz}$ at temperatures above $-60{ }^{\circ} \mathrm{C}$ which is out of measurement frequency of our device. These peaks at low and high frequency regions demonstrate us that the mobility of ion migration from short time constant to long time constant passes via reducing frequency. The peak height in the $M^{\prime \prime}$ versus frequency curves is proportional to capacitance, $C^{-1}$, i.e. $M^{\prime \prime}{ }_{\max }=C_{0} / 2 C$ and here $C_{0}$ is the empty capacitance of sample. 

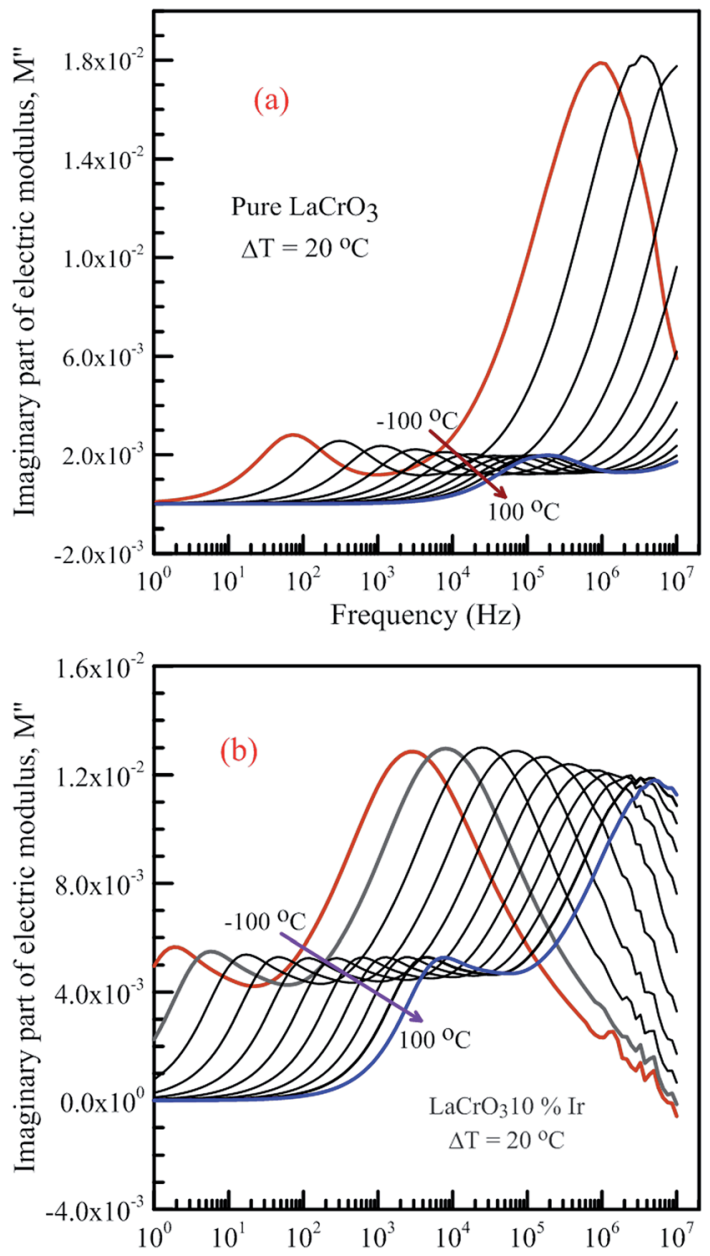

Fig. 7 Frequency dependence plots of the imaginary part of electrical modulus, $M^{\prime \prime}$ in the temperature range from $-100{ }^{\circ} \mathrm{C}$ to $100{ }^{\circ} \mathrm{C}$ with steps of $20{ }^{\circ} \mathrm{C}$, (a) pure $\mathrm{LaCrO}_{3}$ and (b) $\mathrm{LaCr}_{0.90} \mathrm{Ir}_{0.10} \mathrm{O}_{3}$.

Fig. 8 represents the frequency dependent-electrical modulus plane plots of both samples, the imaginary $M^{\prime \prime}$ versus real $M^{\prime}$ curves in the temperature range from $-100^{\circ} \mathrm{C}$ to $100^{\circ} \mathrm{C}$, (a) the parent LCO, inset: low frequency data of the complex electric modulus plane plot of LCO, and (b) the Ir doped LCO. The intercept on the real axis gives the capacitance from the grain or grain boundary. The semicircular arcs have been observed in the modulus plane plot of both samples in low and high frequencies, which points the presence of two relaxation processes. The small semicircular arcs at low frequency correspond to the contribution of weak grain boundary effects rather than the dominant grain effects. The large semicircular arcs at high frequency represent the bulk or grain response. ${ }^{17-24,31} \mathrm{~A}$ deviation from the semicircular shape of modulus arc of both samples has been observed with increasing temperature in high frequency region, and the semicircular arc for LCO sample has only formed at -100 and $-80{ }^{\circ} \mathrm{C}$, though the semicircular arc for the Ir doped LCO sample has only formed at the other frequencies except 60,80 and $100{ }^{\circ} \mathrm{C}$.

The activation energy $E_{\mathrm{a}}$ of the LCO and Ir doped LCO samples have been calculated by using $M^{\prime \prime} v$ s. frequency plots.
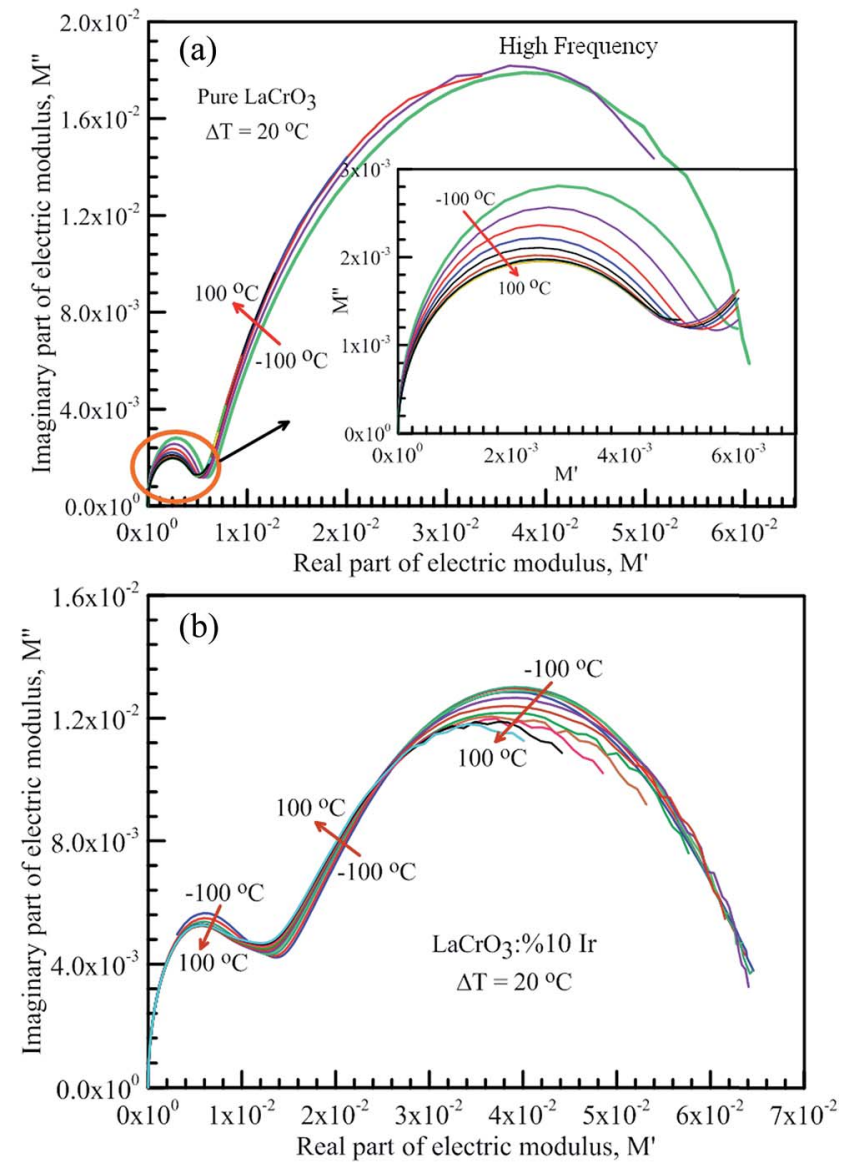

Fig. 8 Frequency dependent-electrical modulus plane plots, the imaginary $M^{\prime \prime}$ versus real $M^{\prime}$ in the temperature range from $-100^{\circ} \mathrm{C}$ to $100^{\circ} \mathrm{C}$ with steps of $20^{\circ} \mathrm{C}$, (a) pure $\mathrm{LaCrO}_{3}$, inset: low frequency data of the complex electric modulus plane plot of the pure LCO sample, and (b) $\mathrm{LaCr}_{0.90} \mathrm{Ir}_{0.10} \mathrm{O}_{3}$ sample.

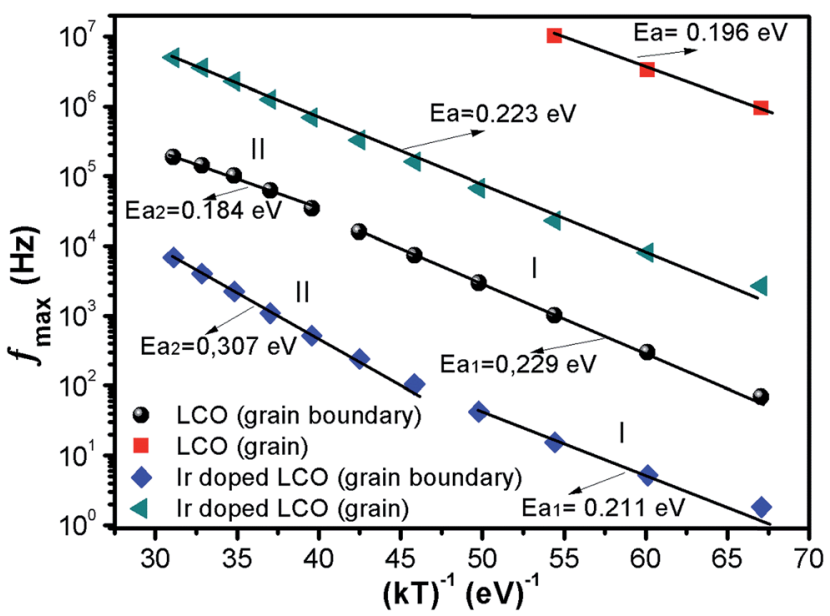

Fig. $9 f_{\max }$ versus $(k T)^{-1}$ plots of both LCO and Ir doped LCO samples. The solid lines represents the fits to the experimental data. 
Table 1 The activation energy of $\mathrm{LaCrO}_{3}$ and Ir doped $\mathrm{LaCrO}_{3}$ from $f_{\max } \& 1 / k T$ plot

\begin{tabular}{|c|c|c|c|c|c|c|}
\hline \multirow{2}{*}{ Material } & \multicolumn{4}{|c|}{$f_{\max }(\mathrm{Hz})($ at low $f)$} & \multicolumn{2}{|c|}{$f_{\max }(\mathrm{Hz})($ at high $f)$} \\
\hline & \multicolumn{2}{|l|}{$\underline{f_{0}(\mathrm{~Hz})}$} & \multicolumn{2}{|c|}{$E_{\mathrm{a}}(\mathrm{eV})$} & $f_{0}(\mathrm{~Hz})$ & $E_{\mathrm{a}}(\mathrm{eV})$ \\
\hline LCO & $2.28 \times 10^{8}$ & $5.96 \times 10^{7}$ & 0.229 & 0.184 & $4.44 \times 10^{11}$ & 0.196 \\
\hline Ir doped LCO & $1.52 \times 10^{6}$ & $9.58 \times 10^{7}$ & 0.211 & 0.307 & $5.22 \times 10^{9}$ & 0.223 \\
\hline
\end{tabular}

The $M^{\prime \prime} v s$. frequency plots for LCO and Ir doped LCO have two peaks, as can be seen from the Fig. 7. In order to calculate activation energies an Arrhenius formula used that is given in eqn (3).

$$
f_{\max }=f_{0} \mathrm{e}^{\left(-\frac{E_{\mathrm{a}}}{k_{\mathrm{B}} T}\right)}
$$

here frequency $f_{\max }$, at which the maximum $M^{\prime \prime}$ takes place, $f_{0}$ is a constant related to frequency, $E_{\mathrm{a}}$ is activation energy, $k_{\mathrm{B}}$ and $T$ are Boltzmann constant and temperature in kelvin scale, respectively. It can be noticed from the Fig. 7 each compounds have two different $\left(f_{\max }\right)$ that one corresponds for low frequency (grain boundary) and other originates higher frequency (grain) regions. The peak at low frequency region suggests that ions move over long distance while the peak at high frequency region proposes that ions move short distance due to confinement in their potential well. ${ }^{57}$ It can be seen from the Fig. 7 that the undoped LCO has just 3 relaxation peaks at higher frequency region (at $-100,-80$ and $-60{ }^{\circ} \mathrm{C}$ ) hence we have just 3 points in the graph. The activation energies of the LCO and Ir doped LCO compounds can be inferred from the slope of $\log \left(f_{\max }\right) v s .(k T)^{-1}$ plots, as exhibited in Fig. 9. The obtained $E_{\mathrm{a}}$ and $f_{0}$ values are presented in Table 1. As can be seen from the Fig. 9 different activation energy values obtained from the slope of $\log \left(f_{\max }\right) v s$. $(k T)^{-1}$ plots. There are two different slope regions (I and II) at low frequency region (grain boundary) whereas only there is a single slope at high frequency region (grain) for both compounds. In our previous study, various activation energies have been attributed to different charge transportation mechanisms. ${ }^{58}$ The calculated activation energy values of $0.229 \mathrm{eV}$ and $0.184 \mathrm{eV}$ at regions I and II at low frequency (or grain boundary) regions and $0.196 \mathrm{eV}$ at high frequency (or grain) region for LCO, $0.211 \mathrm{eV}$ and $0.307 \mathrm{eV}$ at regions I and II at low frequency (or grain boundary) regions and $0.223 \mathrm{eV}$ at high frequency (or grain) region for Ir doped LCO obtained from the slope of $\log \left(f_{\max }\right)$ vs. $(k T)^{-1}$ plots. The calculated activation energies for undoped and doped LCO are good agreement with other studies. ${ }^{\mathbf{5 9 , 6 0}}$ The activation energies of Ir doped LCO
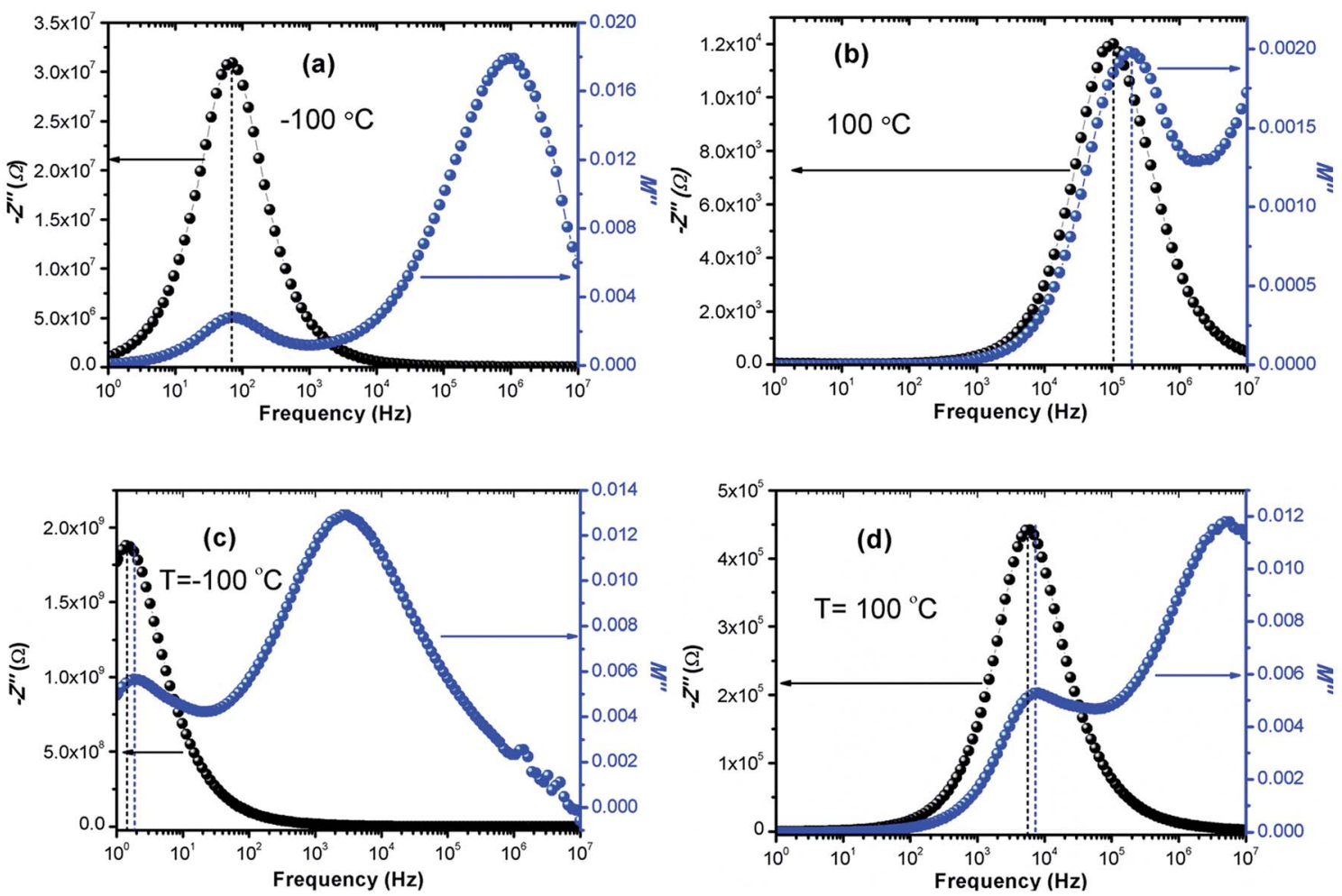

Fig. $10 Z^{\prime \prime}$ and $M^{\prime \prime}$ vs. frequency plots (a) $-100^{\circ} \mathrm{C}$, (b) $100^{\circ} \mathrm{C}$ for $\mathrm{LCO}$ and (c) $-100^{\circ} \mathrm{C}$, (d) $100^{\circ} \mathrm{C}$ for Ir doped LCO compounds. 
higher than that of undoped LCO for all regions except region I (low frequency region). The increment of activation energy with Ir substitution to LCO might be explained by two factors: first may be attributed decreasing concentration of oxygen vacancies in the structure. ${ }^{61}$ LCO is the p-type perovskite when $\mathrm{Ir}^{4+}$ substitutes $\mathrm{Cr}^{3+}$, a positive charge forms at $\mathrm{Ir}$ site so $\mathrm{Ir}^{4+}$ behaves like a donor, and in order to maintain charge neutrality an electron will be created. ${ }^{61}$ This electron neutralizes the influence or contribution of hole. Consequently the concentration of oxygen vacancies diminishes and conductivity decreases or activation energy increases with doping Ir. Second might be ascribed to lattice distortion or defects owing to the Ir substitution into Cr. Our XPS data have exhibited the existence of $\mathrm{Cr}^{3+}$ (61.34\%) (with ionic radius of $0.0615 \mathrm{~nm}$ ) and $\mathrm{Cr}^{6+}(38.66 \%)$ (with ionic radius of $0.044 \mathrm{~nm}$ ) mixed state in Ir doped LCO sample. Additionally, the same study has demonstrated Ir has also mixed oxidation states, $\operatorname{Ir}^{4+}(71.9 \%)$ (with ionic radius of $0.0625 \mathrm{~nm}$ ) and $\operatorname{Ir}^{0}(28.1 \%$ ) (with ionic radius of $0.18 \mathrm{~nm})$. As it can be seen there is a significant distortion and strain can be expected in LCO lattice after Ir doped.

The calculated activation energy values show that the hopping charged particles over the potential barrier are the origin of conduction mechanism for our compounds. ${ }^{62}$ Fig. 10 shows the $Z^{\prime \prime}$ and $M^{\prime \prime} v s$. frequency plots at $-100{ }^{\circ} \mathrm{C}$ and $100{ }^{\circ} \mathrm{C}$ for LCO and Ir doped LCO compounds. It is noticed from these plots, the $Z^{\prime \prime}$ has single peak whereas the $M^{\prime \prime}$ has two peaks, one of them is at low frequency region other is at high frequency region. It can be seen from Fig. 10(a) the peak of $Z^{\prime \prime}$ and $M^{\prime \prime}$ (low frequency peak) vs. frequency occurs at same frequency at $-100{ }^{\circ} \mathrm{C}$ for LCO that suggests a delocalized relaxation mechanism and having long-range mobility. ${ }^{63}$ On the other hand, this behavior has not been observed for LCO at $100{ }^{\circ} \mathrm{C}$ (Fig. 10(b)) also at $-100{ }^{\circ} \mathrm{C}$ and $100{ }^{\circ} \mathrm{C}$ for Ir doped LCO (a slight mismatch can be clearly seen from Fig. 10(b-d)) which suggests localized relaxation mechanism of long-range interaction. ${ }^{63}$

Relaxation time $(\tau)$ can be inferred using the formula $\omega_{\max } \tau$ $=\left(2 \pi f_{\max }\right) \tau=1$ in each peaks in the $M^{\prime \prime} v s$. frequency plots.
Fig. 11(a) and (b) show the $M^{\prime \prime} v s$. frequency behavior for LCO and Ir doped LCO just at $-100{ }^{\circ} \mathrm{C}$ and the relaxation points $\left(\omega_{\max } \tau=1\right)$ can be clearly seen for each compounds. I seen from Fig. 11 (inset figures) equivalent circuit composed from a two parallels RC elements that are connected in series. The relaxation time can be defined in terms of resistance $(R)$ and capacitance $(C)$ which are originating from grain and grain boundary as shown below:

$$
\begin{gathered}
\tau=R C \\
\tau_{\mathrm{g}}=R_{\mathrm{g}} C_{\mathrm{g}}, \tau_{\mathrm{gb}}=R_{\mathrm{gb}} C_{\mathrm{gb}}
\end{gathered}
$$

where $\tau_{\mathrm{g}}, \tau_{\mathrm{gb}}, C_{\mathrm{g}}, C_{\mathrm{gb}}, R_{\mathrm{g}}$ and $R_{\mathrm{gb}}$ relaxation time of grain, relaxation time of grain boundary, capacitance of grain, capacitance of grain boundary, resistance of grain and resistance of grain boundary respectively. The real and imaginary part of electrical modulus can be rewritten, in terms of parameters mentioned above, as shown below:

$$
\begin{aligned}
M^{\prime} & =\frac{C_{0}}{C}\left[\frac{(\omega R C)^{2}}{1+(\omega R C)^{2}}\right] \\
& =\frac{C_{0}}{C}\left[\frac{\left(\omega R_{\mathrm{g}} C_{\mathrm{g}}\right)^{2}}{1+\left(\omega R_{\mathrm{g}} C_{\mathrm{g}}\right)^{2}}\right]+\frac{C_{0}}{C}\left[\frac{\left(\omega R_{\mathrm{gb}} C_{\mathrm{gb}}\right)^{2}}{1+\left(\omega R_{\mathrm{gb}} C_{\mathrm{gb}}\right)^{2}}\right] \\
M^{\prime \prime} & =\frac{C_{0}}{C}\left[\frac{\omega R C}{1+(\omega R C)^{2}}\right] \\
& =\frac{C_{0}}{C}\left[\frac{\omega R_{\mathrm{g}} C_{\mathrm{g}}}{1+\left(\omega R_{\mathrm{g}} C_{\mathrm{g}}\right)^{2}}\right]+\frac{C_{0}}{C}\left[\frac{\omega R_{\mathrm{gb}} C_{\mathrm{gb}}}{1+\left(\omega R_{\mathrm{gb}} C_{\mathrm{gb}}\right)^{2}}\right]
\end{aligned}
$$

The capacitance values are determined using the $M^{\prime \prime} v s$. frequency plots due to the relation between $M^{\prime \prime}=C_{0} / 2 C$ at the relaxation points $\left(\omega_{\max } \tau=1\right)$ mentioned before. The calculated capacitance values for grain $\left(C_{\mathrm{g}}\right)$ and grain boundary $\left(C_{\mathrm{gb}}\right)$ are listed in Table 2. Now, we can calculate the resistance values for grain $\left(R_{\mathrm{g}}\right)$ and grain boundary $\left(R_{\mathrm{gb}}\right)$ using the eqn $(5)$. The
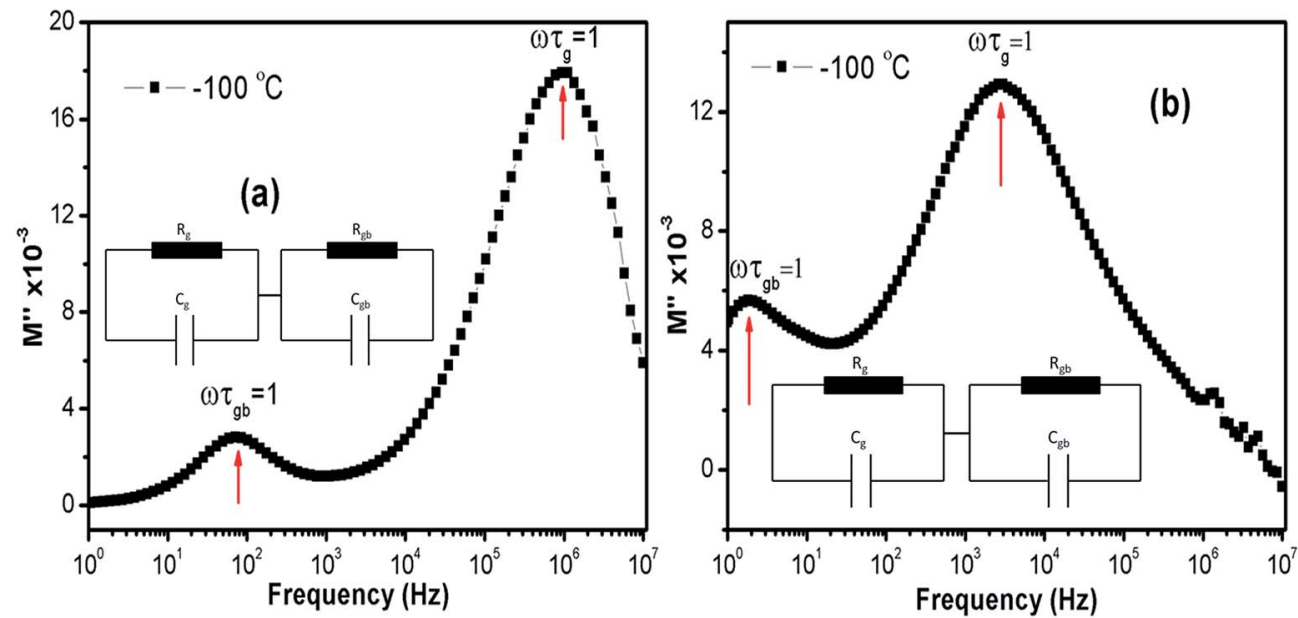

Fig. 11 The $M^{\prime \prime}$ vs. frequency behaviour for LCO and Ir doped LCO just at $-100{ }^{\circ} \mathrm{C}$ and the relaxation points $\left(\omega_{\max } \tau=1\right)$. Inset figures show equivalent circuit for each compounds. 


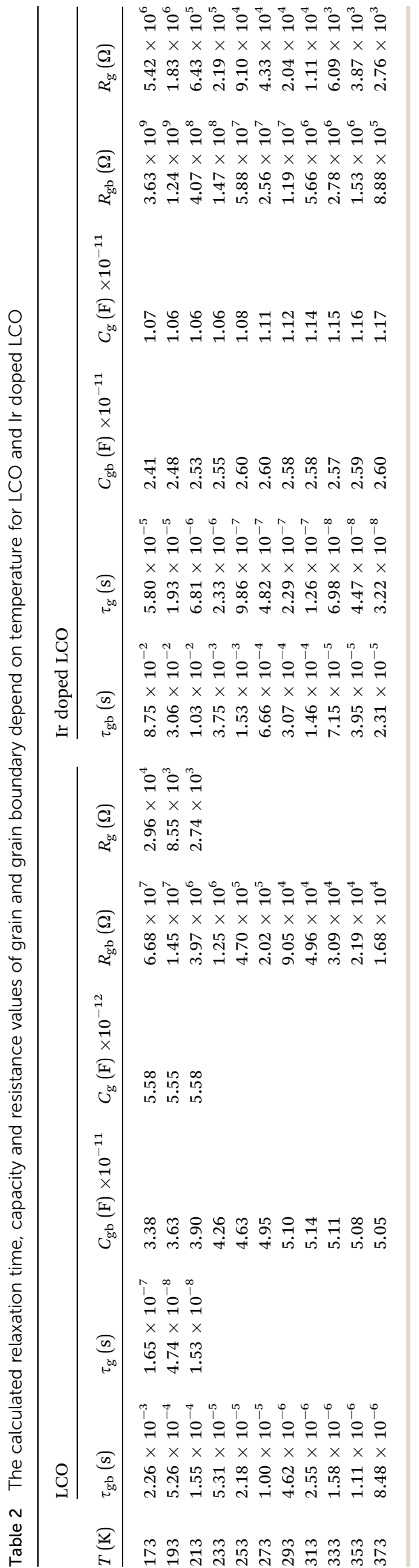

calculated $R$ values were represented with together the capacitance values of $C_{\mathrm{g}}$ and $C_{\mathrm{gb}}$ in Table 2. Temperature dependent $C$ and $R$ plots are given in Fig. 12(a) and (b). It can be clearly seen that $C_{\mathrm{gb}}$ increases with increasing temperature and reaches a maxima then slightly decreasing with increasing temperature, for LCO. The $C_{\mathrm{g}}$ for LCO has just 3 points due to lack of relaxation points of the $M^{\prime \prime} v$ s. frequency plots and as can be seen from the Fig. 12 (a) the $C_{\mathrm{g}}$ is the temperature independent. From the same figure, $C_{\mathrm{gb}}$ shows same behavior with the LCO one for Ir doped LCO and $C_{\mathrm{g}}$ is temperature independent at low temperature regions while slightly increasing with raising temperature at higher temperature regions. The temperature dependent both $R_{\mathrm{g}}$ and $R_{\mathrm{gb}}$ for both compounds show similar behavior decreasing with increasing temperature, as it is observed from Fig. 12(b). Furthermore, it is seen from the same figure, the $R_{\mathrm{gb}}$ is much greater than the $R_{\mathrm{g}}$ for both compounds that grain boundaries behave like insulator while grains behave like semiconductor. ${ }^{64}$

Fig. 13 shows the frequency-dependent plots of the impedance of both samples in the temperature range from $-100{ }^{\circ} \mathrm{C}$ to $100^{\circ} \mathrm{C}$, (a) LCO sample and (b) the Ir doped LCO sample, where $|Z|$ is in terms of a magnitude (absolute value) of the impedance $Z$. Generally, the total impedance acts as pure capacitance at higher frequencies and pure resistance at lower frequencies. Fig. 13(a) and (b) exhibit that the impedance value of both
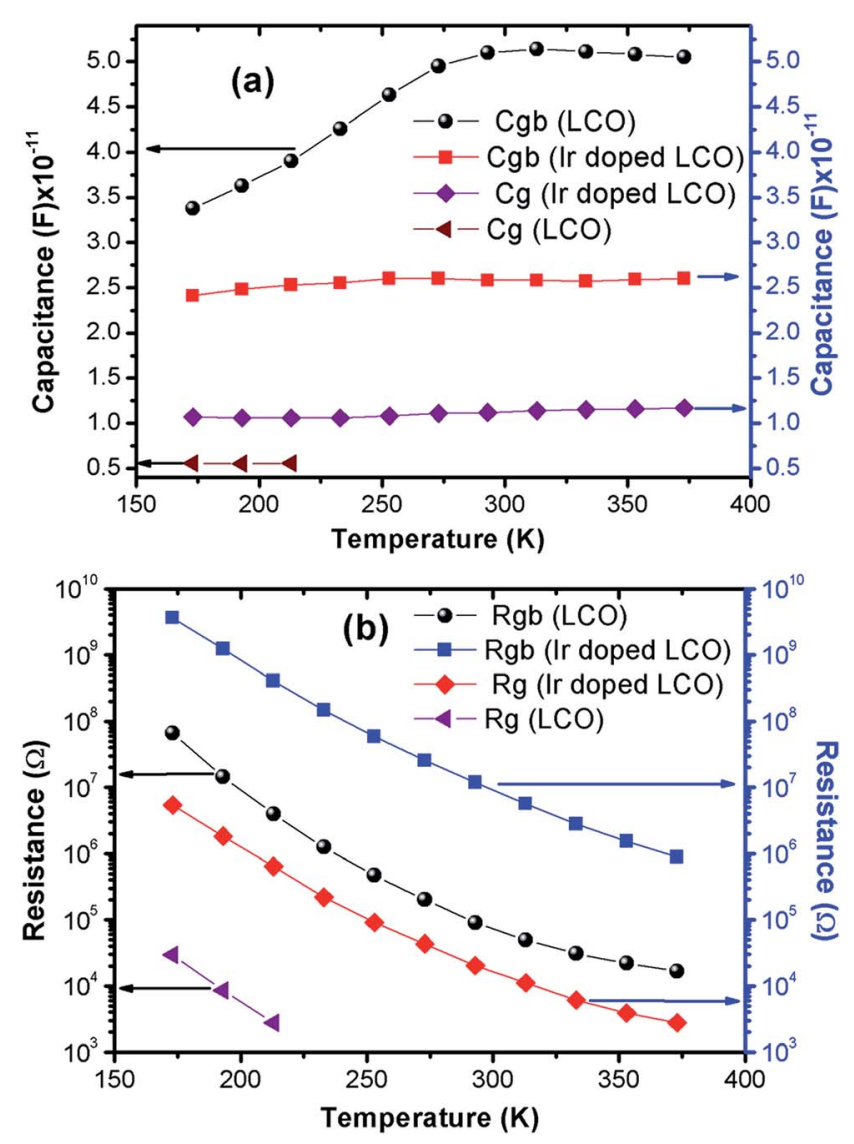

Fig. 12 Temperature dependent (a) capacity and (b) resistance plots of grain and grain boundary for LCO and Ir doped LCO. 

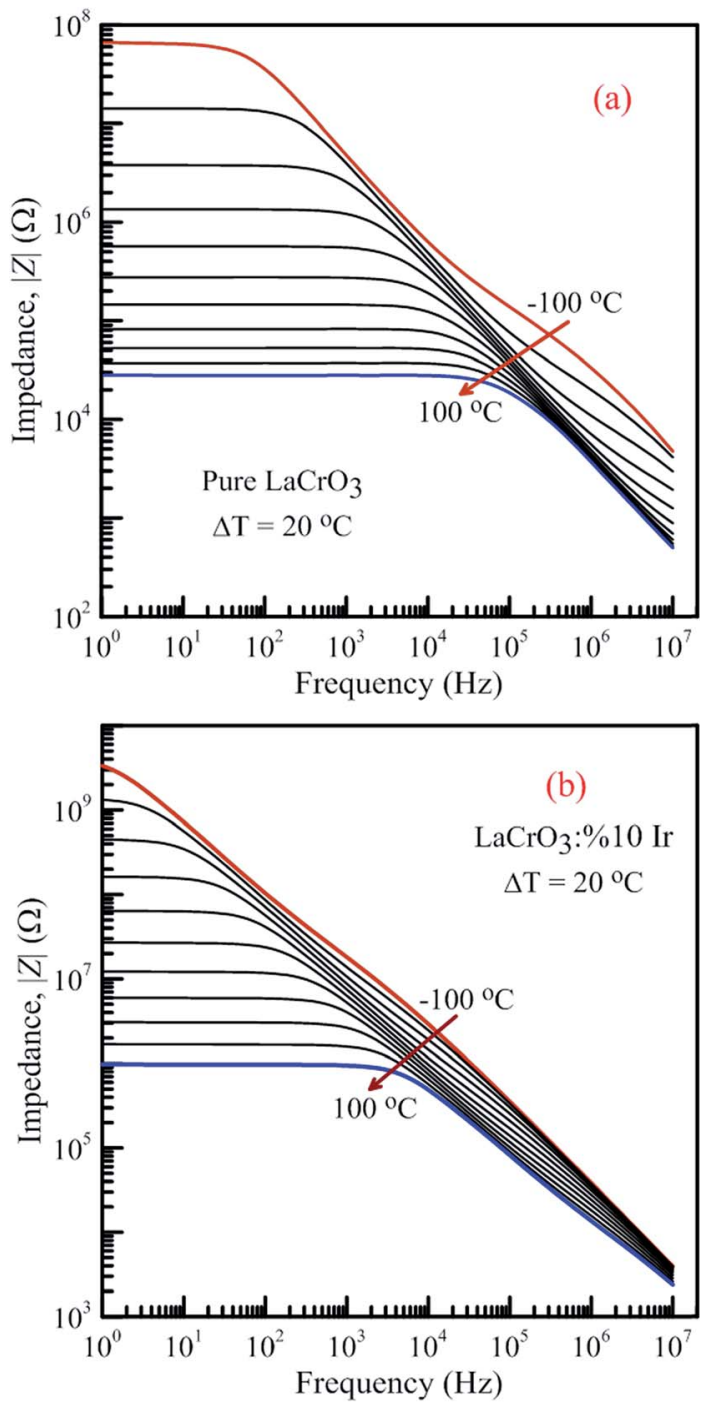

Fig. 13 Frequency dependence of the impedance of both samples in the temperature range from $-100^{\circ} \mathrm{C}$ to $100^{\circ} \mathrm{C}$ with steps of $20^{\circ} \mathrm{C}$, (a) pure $\mathrm{LaCrO}_{3}$ and (b) $\mathrm{LaCr}_{0.90} \mathrm{Ir}_{0.10} \mathrm{O}_{3}$.

samples increases with decreasing temperature at a given frequency. LCO sample has the values of about $6.5 \times 10^{7} \Omega$ at $-100{ }^{\circ} \mathrm{C}$ and $3 \times 10^{4} \Omega$ at $100^{\circ} \mathrm{C}$, and the Ir doped LCO sample has the values of about $3.5 \times 10^{9} \Omega$ at $-100^{\circ} \mathrm{C}$ and $9.5 \times 10^{5} \Omega$ at $100{ }^{\circ} \mathrm{C}$ at low frequency region. That is, the Ir doped LCO sample has higher impedance value than LCO sample at each temperature. Such higher impedance value of Ir doped LCO is most likely attributed to strain and distortion of in LCO crystal structure due to substitution of Ir with larger ionic radius into smaller $\mathrm{Cr}^{3+}$ ion. The presence of distortion probably causes the reduction of the pathway of the mobility charge carriers. As a result, the impedance increases and conduction decreases in the doped LCO sample. It is known that LCO is a p-type compound when $\mathrm{Ir}^{4+}$ substitutes $\mathrm{Cr}^{3+}$, a positive charge forms at Ir site and in order to maintain charge neutrality an electron will be created so $\mathrm{Ir}^{4+}$ behaves like a donor in the LCO. Consequently, every created electron causes decreases conductivity or increases impedance of Ir doped LCO.
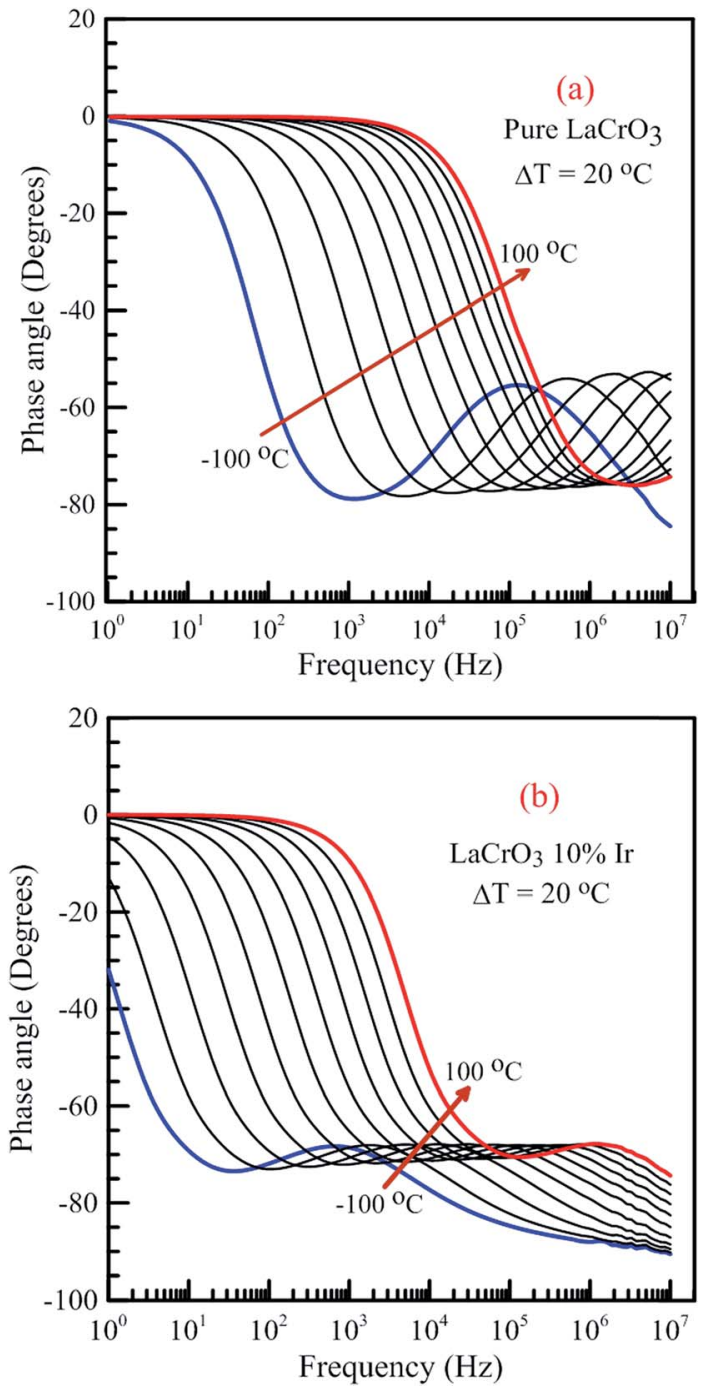

Fig. 14 Frequency dependence of the phase angle of both samples in the temperature range from $-100^{\circ} \mathrm{C}$ to $100^{\circ} \mathrm{C}$ with steps of $20^{\circ} \mathrm{C}$, (a) pure $\mathrm{LaCrO}_{3}$ and (b) $\mathrm{LaCr}_{0.90} \mathrm{Ir}_{0.10} \mathrm{O}_{3}$ samples.

It is obvious from Fig. 13(a) and (b) the total impedance curves behave independent of frequency in low-frequency region and the frequency-dependent at high frequencies. The frequency range of the frequency-independent part of both samples decreases with increasing temperature. The frequency range of the frequency-independent part for LCO sample is wider than that of the Ir doped LCO sample at a given temperature.

Fig. 14 shows the frequency dependence curves of the phase angle in the temperature range from $-100^{\circ} \mathrm{C}$ to $100^{\circ} \mathrm{C}$, (a) LCO and (b) the Ir doped LCO samples. It can be realized from Fig. 14(a) and (b), both samples also have one peak each temperature. The peaks of the Ir doped LCO sample appear in the studied frequency range from $-100{ }^{\circ} \mathrm{C}$ to $100{ }^{\circ} \mathrm{C}$. Nevertheless, the peak of the pure LCO sample shifts towards frequencies over $10^{7} \mathrm{~Hz}$ at temperatures above $-40{ }^{\circ} \mathrm{C}$, that is, out of our measurement frequency range. For both samples, the peak shifts towards high frequencies with increasing 

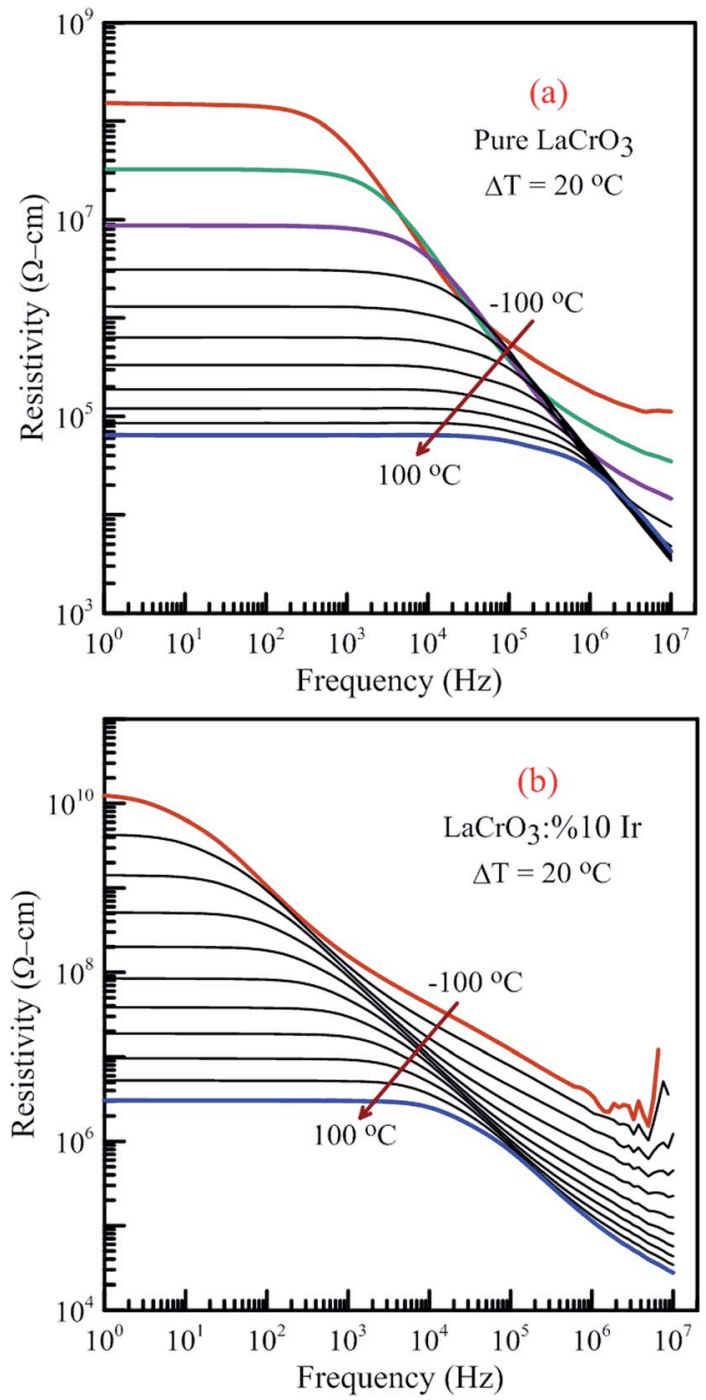

Fig. 15 Frequency dependence of the resistivity of both samples in the temperature range from $-100{ }^{\circ} \mathrm{C}$ to $100{ }^{\circ} \mathrm{C}$ with steps of $20^{\circ} \mathrm{C}$, (a) pure $\mathrm{LaCrO}_{3}$ and (b) $\mathrm{LaCr}_{0.90} \mathrm{Ir}_{0.10} \mathrm{O}_{3}$.

temperature. Another difference appears in the temperaturedependent phase versus frequency curves of both samples. As can be from the these figures, as phase angle, the zero degree starting point for the curves of the parent sample corresponds to $1.0 \mathrm{~Hz}$ at all temperatures; but, for the Ir doped sample it only corresponds to $1.0 \mathrm{~Hz}$ for the curves above $-40{ }^{\circ} \mathrm{C}$, and shifts to lower frequencies than $1.0 \mathrm{~Hz}$ with decreasing temperature at temperatures below $-40{ }^{\circ} \mathrm{C}$. Generally, the phase angle tends to be $-90^{\circ}$ at high frequency that the impedance is completely capacitive, and to $0^{\circ}$ at low frequency that it becomes completely resistive, that is, the impedance approaches the $R$ value at low frequencies.

Fig. 15 illustrates the frequency dependence of the resistivity of both samples in the temperature range from $-100{ }^{\circ} \mathrm{C}$ to $100{ }^{\circ} \mathrm{C}$, (a) LCO sample and (b) the Ir sample doped LCO, respectively. It is well-known the total conductivity or resistivity of the sample composes of the frequency-independent dc bulk compound in low-frequency region and the frequency-

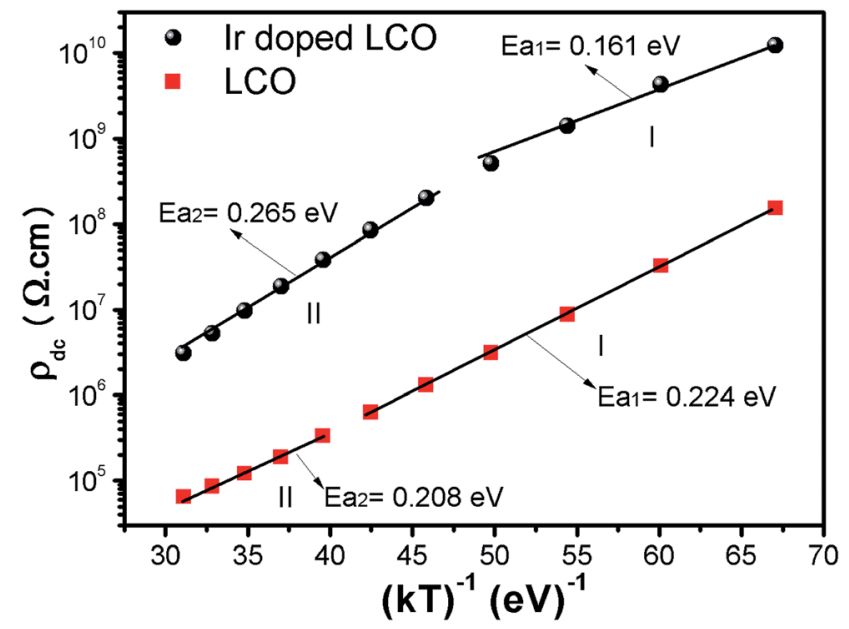

Fig. 16 Resistivity versus $(k T)^{-1}$ plots of both LCO and Ir doped LCO samples. The solid lines represent the fits to the experimental data.

dependent ac component. It is seen from Fig. 15(a) and (b) that the frequency range of the dc compound for LCO sample is wider than that of the Ir doped LCO sample at a given temperature. The resistivity decreases with increasing temperature at each frequency due to the increased mobility of oxygen vacancies or other structural defects. ${ }^{17-23,33,34}$

When Fig. 15(a) and (b) have been considered for the frequency-independent dc compound of the resistivity, $\rho_{\mathrm{dc}}$, LCO sample has the values of around $1.6 \times 10^{8} \Omega \mathrm{cm}$ at $-100^{\circ} \mathrm{C}$ and $6 \times 10^{4} \Omega \mathrm{cm}$ at $100^{\circ} \mathrm{C}$, and the Ir doped LCO sample has the values of about $1.3 \times 10^{10} \Omega \mathrm{cm}$ at $-100^{\circ} \mathrm{C}$ and $2.6 \times 10^{6} \Omega \mathrm{cm}$ at $100^{\circ} \mathrm{C}$. That is, the Ir doped LCO sample has higher $\rho_{\mathrm{dc}}$ value than LCO sample at each temperature. Jiang et al. have also found similar results when they introduced $\mathrm{Ba}^{2+}$ (ionic radius $0.161 \mathrm{~nm}$ ) into $\mathrm{La}^{2+}$ (ionic radius $0.136 \mathrm{~nm}$ ). They have demonstrated that the substitution of $\mathrm{Ba}^{2+}$ has generated distortion in the lattice, which caused scattering of the charge carriers and hence lowered the conductivity. ${ }^{65}$ We believe in Ir doped LCO sample we have similar situation because ionic radii of $\mathrm{Ir}^{4+}$ and $\mathrm{Ir}^{0}$ is larger than $\mathrm{Cr}^{3+}$ and $\mathrm{Cr}^{6+}$ ionic radii. So, there will be important distortion in the LCO lattice owing to Ir substitution. In the present study, the activation energy associated with the bulk conduction has been calculated from the intercept on the resistivity axis of the frequency-independent dc component at each measured temperature. The intercept values have been used for the $\rho_{\mathrm{dc}}$ versus $(k T)^{-1}$ plot related to both samples in Fig. 16. The activation energy, cost must be paid by charge carriers to move inside the material, values of $0.224 \mathrm{eV}$ at low temperature and $0.208 \mathrm{eV}$ at high temperature for LCO, $0.161 \mathrm{eV}$ at low temperature and $0.265 \mathrm{eV}$ at high temperature for Ir doped LCO have been obtained from the slopes of the $\rho_{\mathrm{dc}}$ versus $(k T)^{-1}$ curves, respectively. The obtained activation energy values are in good agreement with previous ones obtained from the slope of $f_{\max } v s .(k T)^{-1}$ curves. ${ }^{61}$ LCO has lower activation energy value at high temperature region than that at the low temperature region whereas the situation for Ir doped LCO is vice versa. The low activation energies show that hopping 
conduction is dominant mechanism for both samples. Materials with higher activation energy have higher resistivity than the materials with lower activation energy value. Therefore, our parent material LCO demonstrates less resistivity than the doped one.

\section{Conclusions}

LCO and 10\% Ir doped LCO samples prepared by the solid state reaction method have exhibited different the dielectric properties from each other. The absolute dielectric constant value of both samples has increased with increasing temperature at a given frequency and it has decreased due to the doping Ir. A plateau region seems in the $M^{\prime}$ versus $f$ curves of LCO sample while no plateau region almost is visible in those of the Ir doped LCO one at each temperature. The imaginary $M^{\prime \prime}$ versus $f$ curves have two peaks at each temperature, one of the peaks has appeared at low frequency and other at high frequency region which shift through higher frequency region with increasing temperature. This originates from free charge accumulation at the interface with the increase of the temperature. The second peak for LCO sample shifts towards frequencies over $10 \mathrm{MHz}$ at temperatures above $-60{ }^{\circ} \mathrm{C}$, that is, out measurement frequency; but, both peaks of the Ir doped LCO sample also appear in the studied frequency range, 1.0 to $10 \mathrm{MHz}$. A deviation from the semicircular shape of modulus arc of both samples has been observed with increasing temperature in high frequency region, and the semicircular arc for LCO sample have only formed at -100 and $-80^{\circ} \mathrm{C}$, and the semicircular arc for the Ir doped LCO one has only formed at the other frequencies except 60,80 and $100{ }^{\circ} \mathrm{C}$. The absolute value of impedance curves behaves independent of frequency in low-frequency region and the frequency-dependent at high frequencies. Moreover, it increases with decreasing temperature at a given frequency, and it has been seen that the Ir doped LCO sample has higher impedance value than that of LCO sample at the same frequency and temperature. Furthermore, the activation energy values of $0.224 \mathrm{eV}$ and $0.208 \mathrm{eV}$ for the pure LCO and $0.161 \mathrm{eV}$ and $0.265 \mathrm{eV}$ for the Ir doped LCO have been obtained from the slopes of the $\rho_{\mathrm{dc}} v s$. $(k T)^{-1}$ curves, respectively. Also the activation energies were calculated from the slopes of the $f_{\max }$ $v s .(k T)^{-1}$ curves and the obtained results from low frequency region were good agreement with $\rho_{\mathrm{dc}} v s .(k T)^{-1}$ ones.

\section{Conflicts of interest}

There are no conflicts to declare.

\section{Acknowledgements}

This work was supported by The Scientific and Technological Research Council of Turkey (TÜBITAK) through Grant No: $116 \mathrm{~F} 025$.

\section{Notes and references}

1 Y. Chen, H. Qin, C. Shi, L. Li and J. Hu, RSC Adv., 2015, 5, 54710-54716.

2 S. Nasri, A. L. Ben Hafsia, M. Tabellout and M. Megdiche, RSC Adv., 2016, 6, 76659-76665.

3 I. Das, S. Chanda, S. Saha, A. Dutta, S. Banerjee, S. Bandyopadhyay and T. P. Sinha, RSC Adv., 2016, 6, 80415-80423.

4 R. Martınez, A. Kumar, R. Palai, J. F. Scott and R. S. Katiyar, J. Phys. D: Appl. Phys., 2011, 44, 105302.

5 Y. C. Shin, S. Hashimoto, K. Yashiro, K. Amezawa and T. Kawada, ECS Trans., 2016, 72(7), 105-110.

6 P. M. Geffroy, S. Vedraine, F. D. Bouchiat, S. K. Saha, A. Gheno, F. Rossignol, P. Marchet, R. Antony, J. Bouclé and B. Ratier, J. Phys. Chem. C, 2016, 120(50), 28583-28590.

7 N. Orlovskaya, K. Kleveland, T. Grande and M. A. Einarsrud, J. Eur. Ceram. Soc., 2000, 20, 51-56.

8 A. P. Sakhya, D. P. Rai, S. A. Dutta, R. K. Thapa and T. P. Sinha, RSC Adv., 2016, 6, 59988-59997.

9 N. Lee, Y. Lansac, H. Hwang and Y. H. Jang, RSC Adv., 2015, 5, 102772-102779.

10 T. Ishihara, T. Kudo, H. Matsuda and Y. Takita, J. Electrochem. Soc., 1995, 142(5), 1519-1524.

11 J. Ravichandran, W. Siemons, H. Heijmerik, M. Huijbenx, A. Majumdar and R. Ramesh, Chem. Mater., 2010, 22, 3983-3987.

12 N. Erdenee, U. Enkhnaran, S. Galsan and A. Pagvajav, J. Nanomater., 2017, 2017, 9120586, DOI: 10.1155/2017/ 9120586.

13 Y. Kato, Y. Kaneko, H. Tanaka, K. Kaibara, S. Koyama, K. Isogai, T. Yamada and Y. Shimada, Jpn. J. Appl. Phys., 2007, 46, 2157.

14 P. Y. Chu, R. E. Jones, P. Zurcher, D. J. Taylor, B. Jiang, S. J. Gillespie, Y. T. Lii, M. Kottke, P. Fejes and W. Chen, J. Mater. Res., 1996, 11(5), 1065-1068.

15 D. Maurya, C. W. Ahn, S. Zhang and S. Priy, J. Am. Ceram. Soc., 2010, 93(5), 1225-1228.

16 Z. Zhang, Y. Chen, M. O. Tade, Y. Hao, S. Liu and Z. Shao, J. Mater. Chem. A, 2014, 2, 9666-9674.

17 V. F. Lvovich, Impedance Spectroscopy, Applications to Electrochemical and Dielectric Phenomena, John Wiley \& Sons, Inc., 2012.

18 N. Bonanos, B. C. H. Steele, and E. P. Butler, Impedance Spectroscopy Theory, Experiment, and Applications, John Wiley \& Sons, New Jersey, 2005.

19 P. C. Sati, M. Kumar and S. Chhoker, Ceram. Int., 2015, 41, 3227-3236.

20 P. Gogoi, P. Srinivas, P. Sharma and D. Pamu, J. Electron. Mater., 2016, 45, 899.

21 Z. Cao, X. Liu, W. He, X. Ruan, Y. Gao and J. Liu, Phys. B, 2015, 477, 8-13.

22 I. Coondoo, N. Panwar, A. Tomar, A. K. Jha and S. K. Agarwal, Phys. B, 2012, 407, 4712-4720.

23 R. Lefia, F. Ben Nasr, H. Hrichi and H. Guermazi, Optik, 2016, 127, 5534-5541. 
24 H. Saghrouni, S. Jomni, W. Belgacem, N. Hamdaoui and L. Beji, Phys. B, 2014, 444, 58-64.

25 S. Karatas and Z. Kara, Microelectron. Reliab., 2011, 51, 2205.

26 S. S. Fouad, G. B. Sakr, I. S. Yahia, D. M. Abdel-Basset and

F. Yakuphanoglu, Phys. B, 2013, 415, 82.

27 T. Yang and T. Cheng, RSC Adv., 2017, 7, 44659.

28 S. Halder, A. Duttab and T. P. Sinha, RSC Adv., 2017, 7, 43812.

29 R. AL-Wafi, Silicon, 2017, 9, 657-661.

30 M. Anjidania, H. M. Moghaddama and R. Ojani, Mater. Sci. Semicond. Process., 2017, 71, 20.

31 I. Dokme, S. Altındal and M. Gokcen, Microelectron. Eng., 2008, 85, 1910.

32 A. S. Kavasoglu, N. Kavasoglu and G. Oylumoglu, Synth. Met., 2011, 161, 1434-1440.

33 S. T. Dong, N. Sun, B. B. Zhang, F. Zhang, S. H. Yao, J. Zhou, S. T. Zhang, Z. B. Gu, Y. B. Chen and Y. F. Chen, Mater. Res. Bull., 2015, 61, 352.

34 J. Wu and J. Wang, J. Am. Ceram. Soc., 2010, 93, 2795.

35 S. M. Khetre, A. U. Chopade, C. J. Khilare, H. V. Jadhav, P. N. Jagadale and S. R. Bamane, J. Mater. Sci.: Mater. Electron., 2013, 24, 4361-4366.

36 J. W. Fergus, Solid State Ionics, 2004, 171, 1-15.

37 Z. J. Feng and C. L. Zeng, J. Power Sources, 2010, 195, 42424246.

38 K. Wakisaka, H. Kado and S. Yoshikado, Key Eng. Mater., 2003, 248, 121-124.

39 H. L. Zhang, Y. Du, A. Papadogianni, O. Bierwagen, S. Sallis, L. F. J. Piper, M. E. Bowden, V. Shutthanandan, P. V. Sushko and S. A. Chambers, Adv. Mater., 2015, 27(35), 5191-5195.

40 K. R. Talley, S. C. Barron, N. Nguyen, W. Wong-Ng, J. Martin, Y. L. Zhang and X. Song, Solid State Sci., 2017, 64, 7-12.

41 G. Y. Lee, R. H. Song, J. H. Kim, D. H. Peck, T. H. Lim, Y. G. Shul and D. R. Shin, J. Electroceram., 2006, 17, 723.

42 P. Barrozo and J. A. Aguia, J. Appl. Phys., 2013, 113, 17 E309. 43 S. B. Li, C. B. Wang, D. Q. Zhou, H. X. Liu, L. Li, Q. Shen and L. M. Zhang, Ceram. Int., 2018, 44, 550-555.

44 O. Polat, Z. Durmus, F. M. Coskun, M. Coskun and A. Turut, J. Mater. Sci., 2018, 53, 3544-3556.

45 G. Yu, Z. Mingfei, K. Martin and R. Sebastian, Angew. Chem., Int. Ed., 2009, 48, 7879-7883.

46 W. Guanjun, Z. Mingfei, G. T. James, S. G. Gary, S. Jing, L. Jun, S. Tobias and R. Sebastian, Nature, 2014, 514, 475477.
47 Q. Bowen, Y. Hongmei, C. Jun, J. Jia, G. Xueqiang, Y. Dewei, Y. Baolian and S. Zhigang, RSC Adv., 2017, 7, 31574.

48 H. Y. Wei, H. H. Cheng, T. H. Ming, Y. S. Yu and W. Y. Da, Appl. Surf. Sci., 2010, 256, 2705-2710.

49 K. G. Jun, K. I. Young, C. W. Dae and S. Youngku, Mater. Sci. Semicond. Process., 2015, 40, 737-743.

50 A. G. Kochur, A. T. Kozakov, A. V. Nikolskii, K. A. Googlev, A. V. Pavlenko, I. A. Ver-benko, L. A. Reznichenko and T. I. Krasnenko, J. Electron Spectrosc. Relat. Phenom., 2012, 185, 175-183.

51 A. T. Kozakov, A. G. Kochur, A. V. Nicolsky, K. A. Googlev, V. G. Smotrakov and V. V. Eremkin, J. Electron Spectrosc. Relat. Phenom., 2011, 184, 508-551.

52 A. Fujimori, M. Saeki, N. Kimizuka, M. Taniguchi and S. Suga, Phys. Rev. B, 1986, 34, 7318-7328.

53 E. Begreuther, S. Grafström, L. M. Eng, C. Thiele and K. Dörr, Phys. Rev. B, 2006, 73, 155425.

54 A. E. Bocquet, A. Fujimori, T. Mizokawa, T. Saitoh, H. Namatame, S. Suga, N. Kimizuka, Y. Takeda and M. Takano, Phys. Rev. B, 1992, 45, 1561-1570.

55 T. Yamashita and P. Hayes, Appl. Surf. Sci., 2008, 254, 24412449.

56 X. Liu, W. Su, Z. Lu, J. Liu, L. Pei, W. Liu and L. He, J. Alloys Compd., 2000, 305, 21-23.

57 C. Kongfa, H. Junji, A. Na, I. Tatsumi and J. P. San, Int. J. Hydrogen Energy, 2016, 41, 1419-1431.

58 M. Coskun, O. Polat, F. M. Coskun, Z. Durmus, M. Caglar and A. Turut, J. Alloys Compd., 2018, 740, 1012-1023.

59 W. Yin, C. Chen, W. Bai, J. Yang, Y. Zhang, X. Tang, C.-G. Duan and J. Chu, Ceram. Int., 2016, 42, 4298-4305.

60 G.-Y. Lee, R.-H. Song, J.-H. Kim, D.-H. Peck, T.-H. Lim, Y.-G. Shul and D.-R. Shin, J. Electroceram., 2006, 17, 723-727.

61 K. Yoshii, N. Ikeda, Y. Shimojo and Y. Ishii, Mater. Chem. Phys., 2017, 190, 96-101.

62 J. Hou and R. V. Kumar, Ferroelectrics - Physical Effects, ed. M. Lallart, InTech, Croatia, 2011, pp. 243-274, DOI: 10.5772/ 20352.

63 R. A. Kumar, A. Dutta, P. K. Mukhopadhyay and T. P. Sinha, J. Alloys Compd., 2018, 730, 201-207.

64 A. Chandran, M. S. Samuel, J. Koshy and K. C. George, J. Mater. Sci., 2011, 46, 4646-4653.

65 S. P. Jiang, L. Liu, K. P. Ong, P. Wu, J. Li and J. Pu, J. Power Sources, 2008, 176, 82-89. 